\title{
Synergetic cloud fraction determination for SCIAMACHY using MERIS
}

\author{
C. Schlundt, A. A. Kokhanovsky, W. von Hoyningen-Huene, T. Dinter, L. Istomina, and J. P. Burrows \\ Institute of Environmental Physics, University of Bremen, Otto-Hahn-Allee 1, 28359 Bremen, Germany
}

Received: 25 May 2010 - Published in Atmos. Meas. Tech. Discuss.: 19 August 2010

Revised: 31 January 2011 - Accepted: 11 February 2011 - Published: 22 February 2011

\begin{abstract}
Since clouds play an essential role in the Earth's climate system, it is important to understand the cloud characteristics as well as their distribution on a global scale using satellite observations. The main scientific objective of SCIAMACHY (SCanning Imaging Absorption spectroMeter for Atmospheric CHartographY) onboard the ENVISAT satellite is the retrieval of vertical columns of trace gases.

On the one hand, SCIAMACHY has to be sensitive to low variations in trace gas concentrations which means the ground pixel size has to be large enough. On the other hand, such a large pixel size leads to the problem that SCIAMACHY spectra are often contaminated by clouds. SCIAMACHY spectral measurements are not well suitable to derive a reliable sub-pixel cloud fraction that can be used as input parameter for subsequent retrievals of cloud properties or vertical trace gas columns. Therefore, we use MERIS/ENVISAT spectral measurements with its high spatial resolution as sub-pixel information for the determination of MerIs Cloud fRation fOr Sciamachy (MICROS). Since MERIS covers an even broader swath width than SCIAMACHY, no problems in spatial and temporal collocation of measurements occur. This enables the derivation of a SCIAMACHY cloud fraction with an accuracy much higher as compared with other current cloud fractions that are based on SCIAMACHY's PMD (Polarization Measurement Device) data.
\end{abstract}

We present our new developed MICROS algorithm, based on the threshold approach, as well as a qualitative validation of our results with MERIS satellite images for different locations, especially with respect to bright surfaces such as snow/ice and sands. In addition, the SCIAMACHY cloud fractions derived from MICROS are intercompared with other current SCIAMACHY cloud fractions based on

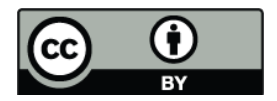

Correspondence to: C. Schlundt (cornelia@iup.physik.uni-bremen.de) different approaches demonstrating a considerable improvement regarding geometric cloud fraction determination using the MICROS algorithm.

\section{Introduction}

Clouds are the subject of interest for the numerical weather prediction, global circulation models, and climate studies. In addition, they are masking/modifying the signal of interest, for instance, in satellite retrievals of snow, land surface or aerosol properties and also trace gas concentrations. It is important to note that the requirement or the quality of the cloud detection algorithm depends on the purpose, which means that either the emphasis is placed on clouds or on clear sky conditions. More precisely, such algorithms can be separated into two classes, namely into "clear sky conservative" (e.g., as needed for aerosol retrievals) or "cloud conservative" (needed for global cloud retrievals) detection algorithms.

In principle, cloud screening algorithms have to deal with various types of clouds. Optically thick and bright clouds are normally well detectable, whereas optically thin clouds usually show a portion of the underlying surface spectral properties leading to difficulties regarding their identification. Another challenging issue is the detection of clouds over bright surfaces such as snow, ice, bright sand, sun glint and turbid water, which also appear bright like clouds. Moreover, cloud borders and cloud shadows need also to be taken into account. Note that undetected clouds or partly cloudy pixels mess up high level products retrieval, which implies the need for accurate cloud screening algorithms.

Most of the current SCIAMACHY cloud fraction algorithms are based on the analysis of measurements performed by the polarization measurement devices (PMDs). This is due to the higher spatial resolution of PMDs compared to the science channels of SCIAMACHY. Then a set of thresholds

Published by Copernicus Publications on behalf of the European Geosciences Union. 
Table 1. Table of optical parameters of the SCIAMACHY instrument.

\begin{tabular}{|c|c|c|c|c|}
\hline & Channel & Spectral range $(\mathrm{nm})$ & Resolution (nm) & Stability (nm) \\
\hline \multirow{8}{*}{$\begin{array}{l}\text { High-resolution } \\
\text { channels }\end{array}$} & 1 & $240-314$ & 0.24 & 0.003 \\
\hline & 2 & 309-405 & 0.26 & 0.003 \\
\hline & 3 & $394-620$ & 0.44 & 0.004 \\
\hline & 4 & $604-805$ & 0.48 & 0.005 \\
\hline & 5 & $785-1050$ & 0.54 & 0.005 \\
\hline & 6 & $1000-1750$ & 1.48 & 0.015 \\
\hline & 7 & 1940-2040 & 0.22 & 0.003 \\
\hline & 8 & $2265-2380$ & 0.26 & 0.003 \\
\hline \multirow{7}{*}{$\begin{array}{c}\text { Polarization } \\
\text { measurement } \\
\text { devices }\end{array}$} & PMD1 & $310-377$ & \multicolumn{2}{|c|}{ broadband } \\
\hline & PMD2 & $450-525$ & \multicolumn{2}{|c|}{ broadband } \\
\hline & PMD3 & $617-705$ & \multicolumn{2}{|c|}{ broadband } \\
\hline & PMD4 & $805-900$ & \multicolumn{2}{|c|}{ broadband } \\
\hline & PMD5 & $1508-1645$ & \multicolumn{2}{|c|}{ broadband } \\
\hline & PMD6 & $2265-2380$ & \multicolumn{2}{|c|}{ broadband } \\
\hline & PMD7 & $802-905$ & \multicolumn{2}{|c|}{ broadband } \\
\hline \multirow{2}{*}{$\begin{array}{c}\text { Radiometric } \\
\text { accuracy }\end{array}$} & & $2-4 \%$ & \multirow{2}{*}{\multicolumn{2}{|c|}{$\begin{array}{l}\text { absolute } \\
\text { relative }\end{array}$}} \\
\hline & & $<1 \%$ & & \\
\hline
\end{tabular}

and constraints is used in order to determine the cloud fraction (Tuinder et al., 2004; Loyola, 2004; Krijger et al., 2005; Grzegorski et al., 2006; Rozanov et al., 2006; Lotz et al., 2009). Moreover, some of the existing trace gas retrievals are making use of the SCIAMACHY cloud fraction derived from the FRESCO algorithm, which determines an "effective" cloud fraction using the oxygen A band under the assumption of an a priori chosen cloud albedo of 0.8 (Koelemeijer et al., 2002). The approaches mentioned above do not permit the determination of the geometric cloud fraction due to a priori chosen parameters or the limited spatial resolution of the PMDs $\left(225 \mathrm{~km}^{2}\right)$.

Since accurate cloud information is needed for reliable aerosol, trace gas and cloud optical property retrievals, we are aimed at improving the current MERIS cloud screening algorithm (Kokhanovsky et al., 2009) in order to improve the accuracy of the SCIAMACHY cloud fraction for the ground pixels at nadir observation. Therefore, in this paper we present a newly developed algorithm for determining a more accurate geometric cloud fraction for SCIAMACHY ground scenes at nadir using MERIS spectral measurements, which we have called MICROS, i.e. MERIS cloud fraction for SCIAMACHY. The SCIAMACHY cloud fraction derived from MICROS serves later as an input parameter for the SACURA (Semi-Analytical CloUd Retrieval Algorithm) algorithm (Kokhanovsky et al., 2003; Rozanov and Kokhanovsky, 2004) and BAER (Bremen AErosol Retrieval algorithm) algorithm (von Hoyningen-Huene et al., 2003), both of which have been developed at the Institute of Environmental Physics and Remote Sensing (IUP) at the University of Bremen.
The paper is organized as follows. A brief explanation of the main technical background information about the SCIAMACHY and MERIS instruments used within this study is given in the next section. Additionally, we provide some basic facts about the AATSR/ENVISAT instrument, since its thermal infrared measurements are used for the qualitative validation of the cloud screening results over snow and ice covered regions. In Sect. 3 a detailed description of the MICROS algorithm can be found. Afterwards, the results of MICROS are discussed by comparing the MERIS cloud screening and its corresponding SCIAMACHY cloud fraction results with MERIS satellite imagery and AATSR/ENVISAT observations. Moreover, we present an intercomparison of the MICROS derived SCIAMACHY cloud fractions with other current SCIAMACHY cloud fractions based on different algorithms. Finally, the paper closes with conclusions and an outlook.

\section{Instruments}

\subsection{SCIAMACHY}

SCIAMACHY (SCanning Imaging Absorption spectroMeter for Atmospheric CHartographY) is a passive hyper spectral UV/VIS/NIR (240-2380 nm) grating spectrometer (Bovensmann et al., 1999). The instrument is onboard ENVironmental SATellite (ENVISAT) which was launched on 1 March 2002. It measures the solar radiation transmitted, backscattered and reflected from the Earth's atmosphere or surface at a relatively high spectral resolution (see Table 1). The instrument performs its measurements in three different viewing 
geometries: nadir, limb and solar/lunar occultation. However, in this study only the nadir observations with a spatial resolution of $30 \mathrm{~km}$ along track, by $60 \mathrm{~km}$ across track, are considered. Such a large pixel size is needed to increase the sensitivity of the instrument to low variations in trace gas concentrations. It is important to note that the retrieval of tropospheric constituents is influenced and limited by clouds. Hence, it is necessary to determine the cloud fraction in the SCIAMACHY ground scene pixel in order to retrieve accurate vertical trace gas columns.

In addition to the 8 science channels, there are 7 broadband detectors which measure the polarization of the incoming light. These are the so-called Polarization Measurement Devices (PMDs). The PMDs cover the spectral range of the main channels but provide a better spatial resolution of approximately $30 \mathrm{~km}$ along track and $7 \mathrm{~km}$ across track, leading to about 8 PMD measurements in one $30 \times 60 \mathrm{~km}^{2}$ ground scene. Due to this higher spatial resolution, PMD measurements are used in most of the current SCIAMACHY cloud fraction algorithms (Krijger et al., 2005; Lotz et al., 2009) as sub-pixel information for the much larger covered areas based on the SCIAMACHY science spectra. In order to further enhance the accuracy of the cloud fraction determined for SCIAMACHY, we use a different approach that is based on the analysis of spectral measurements performed by the MERIS sensor, which is explained in the next subsection.

\subsection{MERIS}

MERIS (MEdium Resolution Imaging Spectrometer) is a multi-spectral instrument, also mounted on the ENVISAT satellite. It measures the solar radiation reflected by the Earth's atmosphere or surface in the visible and near-infrared part of the electromagnetic spectrum between 390 and $1040 \mathrm{~nm}$ (see Table 2) at a spectral resolution of $1.8 \mathrm{~nm}$ (Bezy and Rast, 1999). By looking in the nadir direction, the Earth is imaged with a spatial resolution of $1.2 \times 1.2 \mathrm{~km}^{2}$ at reduced resolution (RR; operational) and $300 \times 300 \mathrm{~m}^{2}$ at full resolution (FR; coastal zones and over land). In this study only the RR data are used. The instrument's field of view is about $68.5^{\circ}$ covering a swath width of $1150 \mathrm{~km}$, which yields a global coverage every three days.

We use the MERIS RR data as sub-pixel information for the relatively large SCIAMACHY pixel which enables the derivation of SCIAMACHY cloud fraction with an accuracy much higher when compared to PMD based cloud fraction. Since the swath width of MERIS is broader than that of SCIAMACHY (swath width $960 \mathrm{~km}$ ), both instruments observe the same ground scene simultaneously.

\subsection{AATSR}

The AATSR (Advanced Along Track Scanning Radiometer) instrument onboard the ENVISAT satellite is a lowresolution conical imaging spectrometer operating in the
Table 2. Table of the MERIS spectral bands and their applications.

\begin{tabular}{|c|c|c|c|}
\hline Band & $\begin{array}{l}\text { Band centre } \\
(\mathrm{nm})\end{array}$ & $\begin{array}{l}\text { Bandwidth } \\
(\mathrm{nm})\end{array}$ & Applications \\
\hline 1 & 412.5 & 10 & Yellow substance \\
\hline 2 & 442.5 & 10 & $\begin{array}{l}\text { Chlorophyll absorp- } \\
\text { tion maximum }\end{array}$ \\
\hline 3 & 490.0 & 10 & $\begin{array}{l}\text { Chlorophyll }+ \text { other } \\
\text { pigments }\end{array}$ \\
\hline 4 & 510.0 & 10 & $\begin{array}{l}\text { Suspended sediment, } \\
\text { red tides }\end{array}$ \\
\hline 5 & 560.0 & 10 & $\begin{array}{l}\text { Chlorophyll absorp- } \\
\text { tion minimum }\end{array}$ \\
\hline 6 & 620.0 & 10 & Suspended sediment \\
\hline 7 & 665.0 & 10 & $\begin{array}{l}\text { Chlorophyll absorp- } \\
\text { tion + fluorescence }\end{array}$ \\
\hline 8 & 681.25 & 7.5 & $\begin{array}{l}\text { Chlorophyll fluores- } \\
\text { cence peak }\end{array}$ \\
\hline 9 & 708.75 & 10 & $\begin{array}{l}\text { Fluorescence refer- } \\
\text { ence, atmospheric } \\
\text { corrections }\end{array}$ \\
\hline 10 & 753.75 & 7.5 & $\begin{array}{l}\text { Vegetation, cloud, } \mathrm{O}_{2} \\
\text { absoption band refer- } \\
\text { ence }\end{array}$ \\
\hline 11 & 760.625 & 3.75 & $\begin{array}{l}\mathrm{O}_{2} \text { R-branch absorp- } \\
\text { tion band }\end{array}$ \\
\hline 12 & 778.75 & 15 & $\begin{array}{l}\text { Atmospheric correc- } \\
\text { tions }\end{array}$ \\
\hline 13 & 865.0 & 20 & $\begin{array}{l}\text { Atmospheric correc- } \\
\text { tions }\end{array}$ \\
\hline 14 & 890.0 & 10 & $\begin{array}{l}\text { Vegetation, water } \\
\text { vapour reference }\end{array}$ \\
\hline 15 & 900.0 & 10 & Water vapour \\
\hline
\end{tabular}

Table 3. Table of the AATSR spectral channels and their applications.

\begin{tabular}{cccl}
\hline Channel & $\begin{array}{c}\text { Centre } \\
\text { Wavelength }\end{array}$ & Bandwidth & $\begin{array}{l}\text { Primary } \\
\text { Application }\end{array}$ \\
\hline $0.55 \mu \mathrm{m}$ & $0.555 \mu$ & $20 \mathrm{~nm}$ & Clorophyll \\
$0.66 \mu \mathrm{m}$ & $0.659 \mu$ & $20 \mathrm{~nm}$ & Vegetation Index \\
$0.87 \mu \mathrm{m}$ & $0.865 \mu$ & $20 \mathrm{~nm}$ & Vegetation Index \\
$1.6 \mu \mathrm{m}$ & $1.61 \mu$ & $0.3 \mu$ & Cloud Clearing \\
$3.7 \mu \mathrm{m}$ & $3.70 \mu$ & $0.3 \mu$ & Sea Surface \\
& & & Temperature (SST) \\
$11 \mu \mathrm{m}$ & $10.85 \mu$ & $1.0 \mu$ & SST \\
$12 \mu \mathrm{m}$ & $12.00 \mu$ & $1.0 \mu$ & SST \\
\hline
\end{tabular}

visible, near-infrared, mid-infrared and thermal spectrum ranges (see Table 3). The prime scientific objective of AATSR is to establish continuity of the ATSR-1 and ATSR2 data sets of precise sea surface temperature (SST), thereby ensuring the production of a unique 10 year near-continuous data set for climate research. The (A)ATSR instruments are 
unique in their use of along track scanning to provide two views of the surface, and thus improve atmospheric correction. The surface is first viewed along the direction of the orbit track, at an angle of $55^{\circ}$ (forward view), as the spacecraft flies towards the scene. Then, $150 \mathrm{~s}$ later, or when the satellite has moved approximately $1000 \mathrm{~km}$ forward along the ground track, a second observation is made of the same scene at the sub-satellite point (nadir view). The nominal pixel size of AATSR is $1 \mathrm{~km}^{2}$ at the centre of the nadir swath and $1.5 \mathrm{~km}^{2}$ at the centre of the forward swath. The AATSR field of view comprises two $512 \mathrm{~km}$ wide curved swaths, with 555 pixels across the nadir swath and 371 pixels across the forward swath. Due to such a narrow swath, AATSR achieves nearly complete global coverage within the 3-day repeat cycle of ENVISAT.

\section{Algorithm}

The size of one SCIAMACHY ground pixel is about $1800 \mathrm{~km}^{2}$ at nadir and consequently, SCIAMACHY spectra obtained by the science channels are not suitable to derive a reliable cloud fraction that can be used as input parameter for subsequent retrievals of vertical trace gas columns. For this reason we utilize MERIS spectral measurements which are located inside of the corresponding SCIAMACHY pixel and define the SCIAMACHY cloud fration $\left(C F_{\text {scia }}\right)$ as the ratio of the number of cloudy MERIS pixels ( $\left.N_{\text {cloudy,meris }}\right)$ to the total number of MERIS pixels $\left(N_{\text {total,meris }}\right)$ inside of the SCIAMACHY pixel:

$C F_{\text {scia }}=\frac{N_{\text {cloudy,meris }}}{N_{\text {total,meris }}}$.

Therefore, it is essential to identify each MERIS pixel as either clear or cloudy before determining $C F_{\text {scia }}$. However, a clear target identification does not only depend on radiometric intensity. Spectral and radiometric conditions for surface and illumination viewing conditions also need to be distinguished for identifying the target as clear or cloudy. Therefore different cases have to be distinguished. The MerIs Cloud fRaction fOr Sciamachy (MICROS) algorithm is used to achieve this goal. The purpose of the MERIS cloud screening, using level $1 \mathrm{~b}$ data (i.e. geolocated and calibrated spectral radiance and irradiance), is to identify each pixel as either clear land, clear water or cloud. Difficulties arise particularly with regard to clouds over bright surfaces, such as snow/ice covered regions, deserts or sunglint areas, which are treated separately by the algorithm as discussed below. The algorithm, based on the threshold approach, is made up of several steps where specific conditions are checked in order to provide index (IDX) values representing sun glint, water, land, bare soil, snow/ice, optically thin and thick clouds (see Table 4).

At the very beginning, each MERIS pixel starts with an index value of 0.0 .
Table 4. Table of used indices for the MERIS pixel classification in the MICROS algorithm.

\begin{tabular}{llc}
\hline 0.0 & Starting Value & Undetermined \\
\hline 1.0 & Snow/Ice & \\
2.0 & Water & \\
3.0 & Bare Soil & Clear Sky \\
5.0 & Land & \\
6.0 & Sun Glint & \\
\hline 7.0 & Optically Thin Cloud & \\
8.0 & Optically Thick Cloud & Cloudy \\
\hline
\end{tabular}

\subsection{Sun glint}

In the first step of the MERIS cloud screening algorithm, the pixel is tested with respect to sun glint (over water) which can be derived from geometrical considerations by checking two criteria. The first criterion states that the solar zenith angle $\left(\vartheta_{0}\right)$ must be equal to the viewing zenith angle $(\vartheta)$ :

$\vartheta_{0}=\vartheta$

Whenever the first condition is fulfilled, the second criterion is checked by calculating the reflection angle $\theta_{r}$ :

$\cos \left(\theta_{r}\right)=\sin (\vartheta) \cdot \sin \left(\vartheta_{0}\right) \cdot \cos (\varphi)+\cos (\vartheta) \cdot \cos \left(\vartheta_{0}\right)$

with $\varphi$ being the relative azimuth angle (solar azimuth angle minus viewing azimuth angle). If the reflection angle exceeds a value of 36.0 (Ackerman et al., 2006), the MERIS pixel is flagged as a sun glint pixel obtaining an index value of 6.0 .

\subsection{Water identification}

The next step of MICROS is related to the water identification, considering oceans as well as inland water by means of a land-water-mask. For this purpose, we incorporated the GTOPO30 model which is a digital elevation model (DEM) for the world, developed by the United States Geological Survey USGS (http://eros.usgs.gov/). This elevation model provides the height above the mean sea level in meters. DEM has a horizontal grid spacing of 30 -arc s (or $\sim 0.008 \dot{3}$ degrees), i.e. approximately $1 \mathrm{~km}$, which makes the model suitable for a geolocation with MERIS pixels due to their spatial resolution of about $1 \mathrm{~km}$.

Since water is generally darker than land surfaces due to the high absorption of water in the near infrared (NIR) wavelength region, the easiest way to identify a water pixel is to check MERIS channels $13(865 \mathrm{~nm})$ and $12(778 \mathrm{~nm})$. If the top-of-atmospere (TOA) reflectance does not exceed a threshold value of 0.08 for channel 13 and 0.09 for channel 12 , the pixel is labelled as water pixel and is assigned with an index value of 2.0. 


\subsection{Land classification}

Afterwards, the MERIS pixel has to pass through the land classification step which also uses the height information derived from the digital elevation model. Since land is generally brighter than water in the NIR wavelength region, the algorithm looks at the same two MERIS channels as used in the previous step. Now, if the TOA reflectance is greater equal 0.09 for channel 13 and 0.08 for channel 12, the pixel is treated as land pixel and is assigned to an index value of 5.0.

The threshold values for the water and land discrimination were found empirically in the framework of the development of the BAER (Bremen AErosol Retrieval) algorithm for the retrieval of aerosol optical depth.

Because bright surfaces can lead to a misclassification with respect to clouds, at this point we introduce the so-called Normalized Difference Vegetation Index NDVI (http://earthobservatory.nasa.gov/Features/ MeasuringVegetation/). It is defined as near-infrared reflectance minus visible reflectance divided by near-infrared reflectance plus visible reflectance. Today, NDVI is widelyused in the analysis of remote sensing measurements since it is a simple numerical approach indicating whether the target being observed contains live green vegetation or not. NDVI reaches negative values (approaching -1 ) for water (ocean, seas, lakes and rivers) due to a rather low reflectance in both spectral bands. The values are generally close to zero $(-0.1$ to +0.1 ) for barren areas of rock, sand or snow. Small positive values $(\sim 0.2$ to 0.4$)$ correspond to shrub and grassland, while high values (approaching 1) relate to temperate and tropical rainforests. Thus, we also incorporated such a vegetation index using MERIS TOA reflectances at $865 \mathrm{~nm}$ (NIR band) and $665 \mathrm{~nm}$ (VIS in the red band) by means of the following formula:

$\mathrm{NDVIX}=\frac{R_{\mathrm{TOA}}(865 \mathrm{~nm})-R_{\mathrm{TOA}}(665 \mathrm{~nm})}{R_{\mathrm{TOA}}(865 \mathrm{~nm})+R_{\mathrm{TOA}}(665 \mathrm{~nm})}$

Hence, for a pixel, which has been identified as clear land pixel (IDX $=5.0$ ) beforehand, MICROS calculates the NDVI and reassigns this pixel to an index value of 3.0, if the NDVI is less than 0.1 indicating a barren area (e.g., desert pixel).

However, NDVI should be handled with care because it is sensitive to several factors, such as atmospheric effects (regarding aerosols and water vapor), thin or small clouds (e.g. cirrus clouds), soil effects (concerning wet soils), anisotropic effects and spectral effects that can lead to misinterpretation of NDVI. Therefore, we note that a barren area pixel identification without the use of a surface reflectance data base is quite challenging in the case of a simple threshold approach. For this reason, a dust index (DI) based on SCIAMACHY NIR measurements is introduced for the SCIAMACHY cloud fraction calculation, which is defined as

$\mathrm{DI}=\frac{<R_{\mathrm{TOA}, \text { scia }}(1560 \mathrm{~nm})>}{<R_{\mathrm{TOA}, \mathrm{scia}}(1624 \mathrm{~nm})>}$
Using DI the algorithm is capable of detecting heavy desert dust storms, which would be otherwise identified as clouds because the reflectivity of desert surfaces can be larger than 0.2 . This index is approximately equal to one for dust, while it is smaller than $\sim 0.7$ for ice clouds and smaller than $\sim 0.9$ for water clouds, respectively (Kokhanovsky et al., 2007). This originates from the fact that dust, unlike water or ice, has no specific absorption features in the spectral range from $1560 \mathrm{~nm}$ to $1625 \mathrm{~nm}$. We apply the dust index only over land and for the latitudinal range of $-50^{\circ}$ to $+50^{\circ}$ because most of the deserts are located in this geographical area. We found that the dust index sometimes fails over water which most probably is related to the inhomogeneity of clouds and varying illumination and viewing conditions. Moreover, the dark underlying surface significantly influences the calculation of the dust index leading to errors in cloud/dust discrimination. The SCIAMACHY cloud fraction is set equal to zero, if DI is greater equal to 0.95 but less than 2.0 regardless of the MERIS derived cloud fraction.

\subsection{Cloud detection}

The next step of MICROS considers cloud detection. In general, clouds are characterized by four simple criteria: clouds are bright, white, cold and higher than the surface of the Earth. Unfortunately, clouds do not always fulfill these characteristics. There are clouds that are warm or at the surface (e.g. mountains) or not very bright. Thus, several tests are necessary in order to classify a pixel as a cloud contaminated or non-cloudy one, which becomes especially difficult over bright surfaces like snow/ice and sand (low contrast in the visible wavelength region).

The MERIS instrument measures up to $900 \mathrm{~nm}$ and consequently, it neither possesses short infrared (SWIR) wavelength bands nor thermal infrared bands which would provide suitable information for the distinction between snow/ice and clouds. Due to this lack of infrared channels, no brightness temperature test can be carried out. The determination of the cloud top height by exploiting the $\mathrm{O}_{2}$ absorption band at $760 \mathrm{~nm}$ (MERIS channel 11) is also very demanding because this channel is strongly influenced by the smile effect. The smile effect is a shift in wavelength in the spectral domain occurring in every push-broom sensor using CCD technique (Bourg et al., 2008). Although the smile effect is small in absolute values $(\sim 1.5 \mathrm{~nm}$ at camera borders, $\sim 1.0 \mathrm{~nm}$ within one camera), it has a large impact on channels having a small spectral bandwidth (like MERIS band 11, see Table 2). Additionally, the effect causes serious problems, if the slope of the measured spectrum is high, and it is amplified when using differences or ratios of two bands. Consequently, an implementation of the ratio of MERIS band $11(760.625 \mathrm{~nm})$ to band $10(753.75 \mathrm{~nm})$ in order to calculate the oxygen absorption depth (a small value indicates clear sky due to high oxygen absorption), would lead to large deviations without an adequate correction 
procedure regarding the MERIS reflectances in channel 11. At the end, only two criteria are left, namely the brightness and whiteness of clouds which are discussed in the following paragraphs. Since the exact definition of a cloud in terms of whiteness and brightness cannot be performed due to the smooth transition from the cloudy to a clear sky case (e.g. consider cloud dissipation events), we introduce several thresholds based on physical assumptions in order to classify cloudy scenes.

\subsubsection{Brightness of clouds}

For the attribute that clouds are bright, we use the assumption that the TOA reflectance $R_{\mathrm{TOA}}$ at channels 2,3 and $4(442.5 \mathrm{~nm}, 490 \mathrm{~nm}$ and $510 \mathrm{~nm})$ exceeds a limit of 0.22 . Then, the pixel is flagged as cloudy (i.e., optically thick cloud) and obtains an index value of 8.0. Over barren areas (IDX $=3.0$ ) we use the same three spectral bands but here we found an empirical threshold value of 0.30 in order to avoid misclassifications.

\subsubsection{Whiteness of clouds}

For the characteristic that clouds are white, we use the spectral contrast (SC) in the blue defined as the ratio of the TOA reflectance of band 1 to band 2:

$\mathrm{SC}=\frac{R_{\mathrm{TOA}}(412.5 \mathrm{~nm})}{R_{\mathrm{TOA}}(442.5 \mathrm{~nm})}$

in combination with the minimal value of TOA reflectances (RMIN) in the spectral interval $412.5 \mathrm{~nm}-753.75 \mathrm{~nm}$ :

$$
\begin{aligned}
\mathrm{RMIN}= & \operatorname{MIN}\left[R_{\mathrm{TOA}}(412.5 \mathrm{~nm}),\right. \\
& R_{\mathrm{TOA}}(442.5 \mathrm{~nm}), \quad R_{\mathrm{TOA}}(560.0 \mathrm{~nm}), \\
& \left.R_{\mathrm{TOA}}(665.0 \mathrm{~nm}), \quad R_{\mathrm{TOA}}(753.75 \mathrm{~nm})\right]
\end{aligned}
$$

For a clear sky case the TOA reflectance at $412.5 \mathrm{~nm}$ is larger than the TOA reflectance at $442.5 \mathrm{~nm}$ due to Rayleigh scattering. For a cloudy case, the spectral contrast drops because molecules are screened by clouds. The SC threshold is necessary in order to distinguish clouds from thick aerosol layers that are located close to the ground. The RMIN threshold allows a separation between thick clouds (e.g. clouds with an optical thickness $\tau$ above 5) and thin clouds (e.g. clouds with $\tau<5)$.

Over ocean, outside of the sun glint affected area, we find for optically thick clouds $(\tau \geq 5)$ that SC should be lower than 1.04 and RMIN larger equal $0.2($ IDX $=8.0)$ and for optically thin clouds $(\tau<5)$ that SC should be lower than 1.04 and RMIN lower than 0.2 (IDX $=7.0$ ), respectively. If IDX is still undetermined, MICROS checks both conditions for SC and RMIN once more, but this time SC should be lower than 1.20 instead of 1.04. The reason for this double checking is related to the position of the sun at nadir observation, i.e. the TOA reflectance is decreasing with increasing solar zenith angles. Generally, $\mathrm{SC}<1.04$ works for all latitudinal regions,

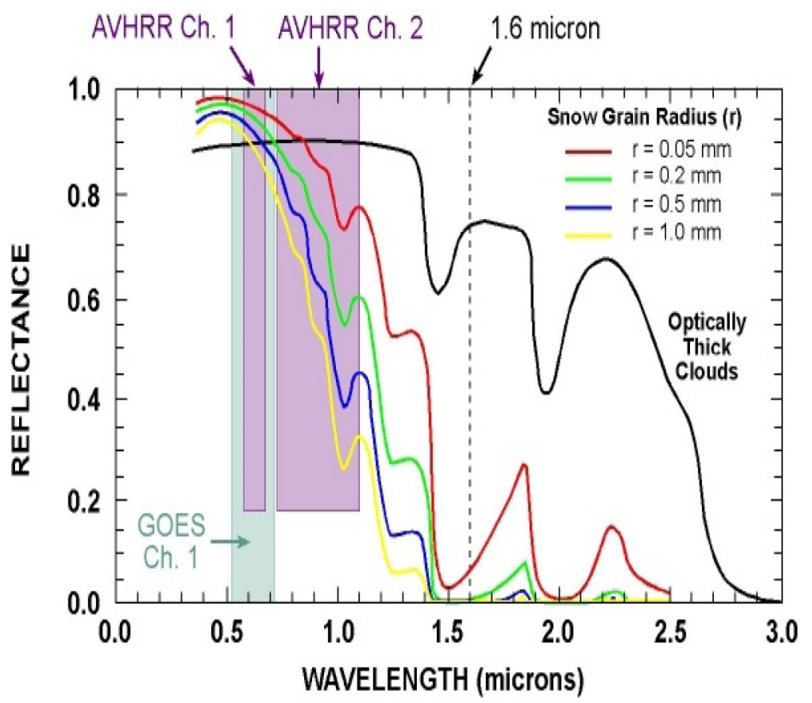

Fig. 1. The reflectance spectrum of clouds and snow for different grain sizes. In the visible and near-infrared both spectra are similar in magnitude and shape but in the shortwave infrared $(1.4-3.0 \mu)$ snow shows a significantly lower reflectivity compared to clouds. (Source: National Snow and Ice Data Center, University of Colorado, 2008).

especially for high latitudes, but at mid- and low-latitudes some of the clouds have not been detected by SC lower than 1.04 since they can have values lower than 1.20 due to higher TOA reflectances. Over land (IDX $=5.0$ ), MICROS treats a pixel as optical thick cloud (IDX $=8.0$ ) if SC is lower than 1.04 and RMIN is larger equal 0.31 . However, the detection of optical thin clouds over land, especially over barren areas of rock, sand or snow, is extremely difficult using a simple threshold approach. In other words, the brightness test is able to identifiy clouds with low optical thicknesses over land as long as the underlying surface is dark enough. In case of a bright surface, the contrast in the visible wavelength region is not high enough for a clear identification.

\subsection{Snow/Ice discrimination}

Last but not least, MICROS checks for snow/ice pixels which is a tough task when using MERIS observations owing to a lack of SWIR bands as already mentionend above in Sect. 3.4. Since the reflectance of snow (and ice) is pretty large as well as spectrally neutral, the algorithm would not detect snow or ice but clouds. Also the spectral contrast in the blue (see Eq. 6) does not significantly differ from that of clouds which can be seen in Fig. 1 showing the reflectance spectrum of clouds and snow for different grain sizes in the wavelength range from 0.4 to 3.0 microns. One can see clearly, that both spectra are similar in magnitude and shape in the VIS and NIR part of the electromagnetic spectrum but differ in the SWIR wavelength region, where snow offers a 


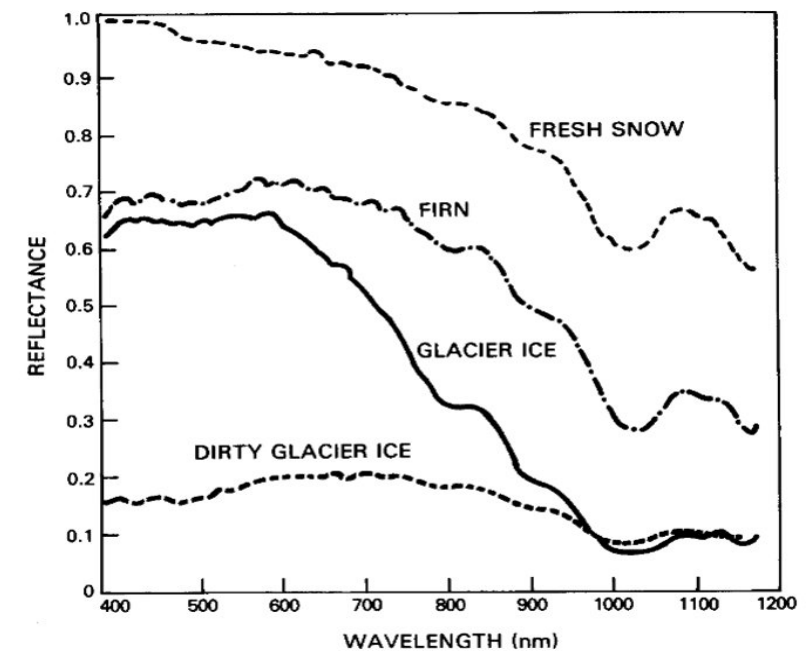

Fig. 2. The spectral dependency of snow and ice depending on their formation stage (Zeng et al., 1983).

considerably lower reflectivity than optically thick clouds. However, MICROS can not make use of this decrease of reflectance from VIS-red or NIR to SWIR compared to other algorithms applied to AATSR, AVHRR or MODIS, where SWIR bands are available (see, e.g., Istomina et al. (2010)).

The MERIS instrument is not designed for the detection of snow and ice, so that the only remaining possibility in the context of a simple threshold approach is the use of the MERIS Differential Snow Index (http://www.brockmann-consult.de/albedomap/ documentation.html), which is defined as:

$\operatorname{MDSIX}=\frac{R_{\mathrm{TOA}}(865.0 \mathrm{~nm})-R_{\mathrm{TOA}}(885.0 \mathrm{~nm})}{R_{\mathrm{TOA}}(865.0 \mathrm{~nm})+R_{\mathrm{TOA}}(885.0 \mathrm{~nm})}$

Thus, MICROS labels a pixel as snow/ice obtaining an index value of 1.0, if the pixel has been proven to be bright beforehand along with a MDSIX value greater than 0.01 .

In general, MDSIX is catching the right snow/ice pixels, which will be demonstrated in Sect. 4.1, whenever there is a negative slope from MERIS band $13(865 \mathrm{~nm})$ towards band $14(885 \mathrm{~nm})$ providing a value above 0.01 , while optically thick clouds show a flat or slightly positive slope between this two channels reaching a negative MDSIX value. However, sometimes MDSIX seems to fail as well. In other words, it happens that clouds are misinterpreted as snow/ice by MDSIX or the other way around, that MDSIX does not recognize snow/ice. This is clearly the case when MICROS has to deal with a mixed pixel (e.g., clouds and snow/ice mixed) instead of a pure snow/ice pixel. Other possible reasons might be related to the different spectral behavior of snow and ice depending on its age, grain size, wetness or degree of pollution. Figure 2 shows the spectral reflectances for fresh snow, firn, glacier ice and dirty glacier ice demonstrating the complexity of the snow/ice discrimination without further information on the spectral behavior in the SWIR wavelength region. We also found that MDSIX detects sea ice only if it is covered with snow, while MDSIX fails in case of fresh sea ice (not covered with snow) which looks dark like water in this case.

In summary, the use of MDSIX for detecting snow/ice is a good solution, but of course it is not the "best" solution for this purpose, because mixed pixels will not give right MDSIX values and the spectral behavior of snow/ice varies over a large range which cannot be covered by VIS and NIR measurements only. Even more difficult is the distinction between snow and ice without SWIR observations. On the one hand, sea ice is often covered by snow or water and on the other hand, their spectral behavior in the VIS and NIR wavelength regions do not offer distinct features which could be used for the discrimination. The purpose of MICROS is the determination of a cloud fraction for SCIAMACHY ground scenes using MERIS observations which means, the algorithm checks each MERIS pixel whether it is cloudy or cloud-free. Consequently, the distinction between clear snow and ice is of no importance in this context.

\subsection{Cloud border and adjacency effects}

The very last step of the cloud screening takes cloud border and adjacency effects (e.g., cloud shadowing or increased radiation by actinic flux) into account, by flagging additional two adjacent MERIS pixels within a radius of $2 \mathrm{~km}$ as cloudy.

\subsection{Cloud fraction for SCIAMACHY ground scene}

Finally, the MERIS cloud fraction for SCIAMACHY is determined based on the pixel classification procedure described above. MICROS provides a thin cloud fraction $\left(C F_{\text {thin,S }}\right)$, a thick cloud fraction $\left(C F_{\text {thick,S }}\right)$ and a total (thin+thick) cloud fraction $\left(C F_{\text {total,S }}\right)$ for each SCIAMACHY ground scene. They are defined as the ratio of the number of cloudy MERIS pixels to the total number of MERIS pixels inside of the corresponding SCIAMACHY pixel as follows:

$$
\begin{aligned}
C F_{\text {thin }, \mathrm{S}} & =\frac{N_{\text {thin, } \mathrm{M}}}{N_{\text {total }, \mathrm{M}}} \\
C F_{\text {thick }, \mathrm{S}} & =\frac{N_{\text {thick, } \mathrm{M}}}{N_{\text {total }, \mathrm{M}}} \\
C F_{\text {total }, \mathrm{S}} & =\frac{N_{\text {thin, } \mathrm{M}}+N_{\text {thick }, \mathrm{M}}}{N_{\text {total }, \mathrm{M}}}
\end{aligned}
$$

As already mentioned in Sect. 3.4, the MERIS cloud screening uses the minimal reflectance value (RMIN) between $412 \mathrm{~nm}$ and $753 \mathrm{~nm}$ in conjunction with the spectral contrast in the blue, in order to distinguish between optically thin $(\mathrm{RMIN}<0.2)$ and thick ( $\mathrm{RMIN} \geq 0.2)$ clouds.

A schematic diagram of the MERIS cloud screening procedure incorporated in the MICROS algorithm is presented in Fig. 3, and a list of the indices used therein is shown in Table 4. 


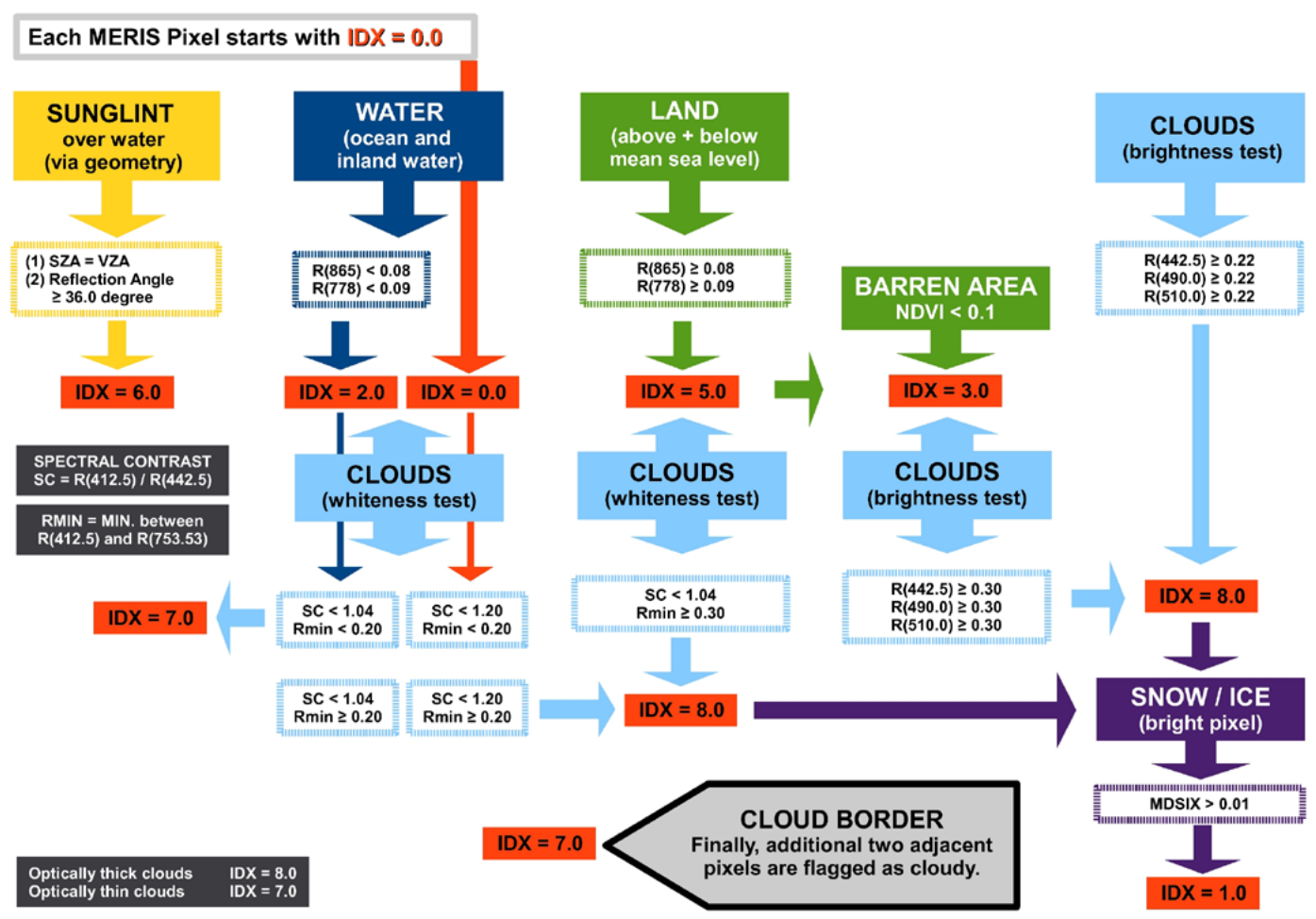

Fig. 3. A scheme illustrating the MERIS pixel classification, based on the threshold method, that is incorporated in the MICROS algorithm. Each MERIS pixels starts with an index value of 0.0 before it passes each step of the MERIS identification routine, where specific conditions are checked in order to provide a certain index (IDX) value. A detailed explanation of the thresholds and constraints used for the pixel classification is given in Sect. 3 .

\section{Results}

\subsection{Qualitative validation}

In order to survey the performance of the MICROS algorithm, we compare the MERIS cloud screening and SCIAMACHY cloud fraction results with MERIS satellite images. The MERIS RGB images are created using the TOA reflectances from the first 8 MERIS bands. Red, green and blue are defined by the following equations:

$$
\begin{aligned}
\text { red }= & \operatorname{alog}(1+ \\
& 0.25 \cdot R(560.0 \mathrm{~nm})+0.65 \cdot R(620.0 \mathrm{~nm})+ \\
& 0.77 \cdot R(665.0 \mathrm{~nm})+0.73 \cdot R(681.25 \mathrm{~nm})) \\
\text { green }= & \operatorname{alog}(1+ \\
& 0.21 \cdot R(490.0 \mathrm{~nm})+0.75 \cdot R(510.0 \mathrm{~nm})+ \\
& 0.67 \cdot R(560.0 \mathrm{~nm})+0.28 \cdot R(620.00 \mathrm{~nm})) \\
\text { blue }= & \operatorname{alog}(1+ \\
& 0.25 \cdot R(412.5 \mathrm{~nm})+0.35 \cdot R(442.5 \mathrm{~nm})+ \\
& 0.67 \cdot R(490.0 \mathrm{~nm})+0.26 \cdot R(510.00 \mathrm{~nm}))
\end{aligned}
$$

Different examples demonstrate the quality of the cloud screening over land and water, whereas emphasis is placed on the cloud detection over barren areas of sand, rock, snow and ice. For each example, a MERIS RGB image with the corresponding MERIS cloud screening and the SCIAMACHY cloud fraction (total) at nadir is shown. Note that the gaps between the nadir states are related to SCIAMACHY limb observations, which are not taken into account in this study.

The maps in Fig. 4 show a section of the orbit 18928 on the 13th of October 2005 covering northern and central Europe. Figure $4 \mathrm{a}$ offers the following features. A huge cloud field is located over Scandinavia exhibiting a few holes in the cloud cover over Sweden. The Baltic Sea, Germany and the Benelux are almost cloud free, while clouds are formed over Poland and central France. Furthermore, some small cloud bands are situated around the Alps and a mixtured of thin and thick clouds occur over the North Sea. By comparing Figure $4 \mathrm{a}$ with Figure 4b, one can see clearly, that the MERIS cloud screening developed by us is indeed capable to detect clouds over land and water, since all features mentioned above are recognizable. Consequently, the SCIAMACHY cloud fraction, illustrated in Fig. 4c, gives very reasonable values.

The maps in Fig. 5 show the continuation of the previous orbit (18928) covering North Africa and the Mediterranean Sea. Figure 5a shows a large thick, bright cloud band that is 
(a)

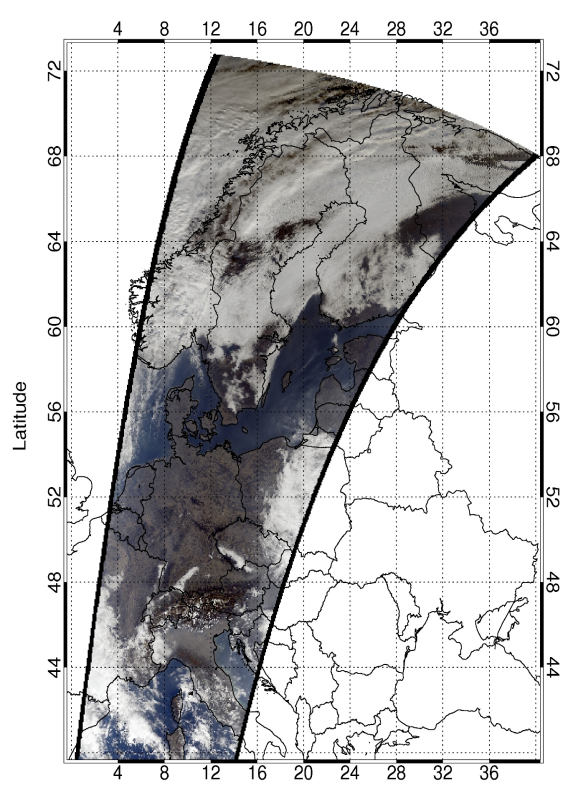

Longitude (b)

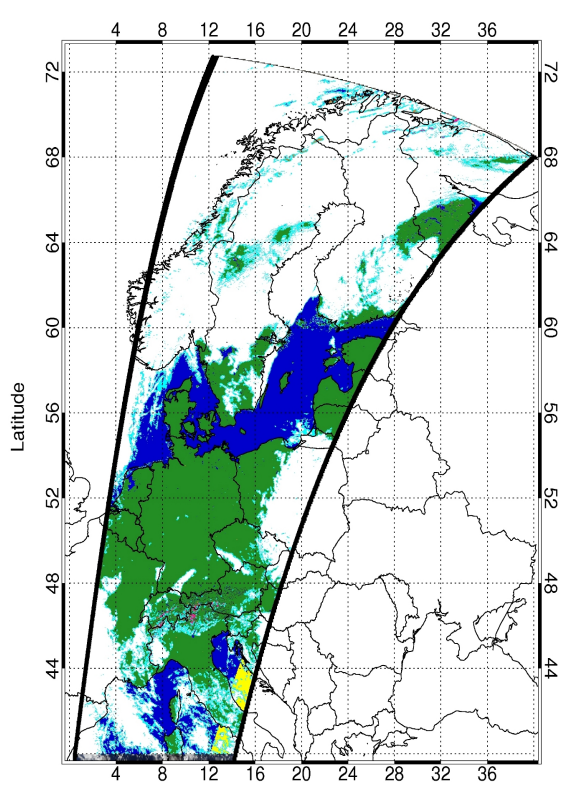

Longitude

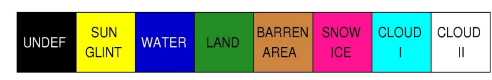

(c)

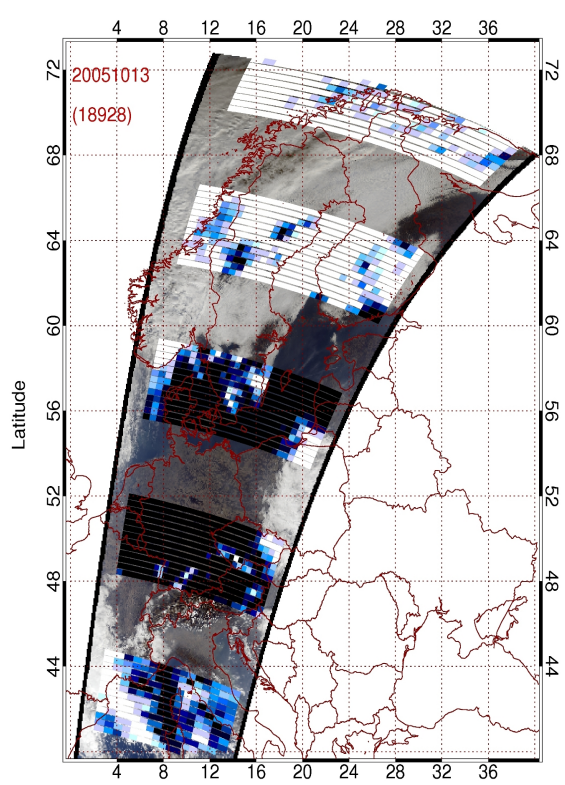

Longitude

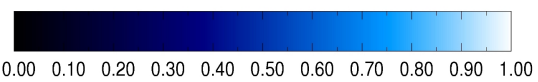

Fig. 4. Maps showing a section of orbit 18928 on the 13th of October 2005 covering northern and central Europe: (a) MERIS RGB image, (b) MICROS-MERIS cloud screening and (c) MICROS-SCIAMACHY cloud fraction (at nadir).

situated over south France extending towards Sardinia. Another bright cloud field has formed over East of Spain which stretches across the Baleares. Overall, the Mediterranean Sea is covered by multiple thin and thick clouds. Moreover, the scene represents a good example for a cloud screening over a bright surface, such as the Sahara desert. One can see a large cloud formation in the North of Algeria as well as some smaller clouds at $28^{\circ} \mathrm{N}, 4^{\circ} \mathrm{E}$ and $24^{\circ} \mathrm{N}, 2^{\circ} \mathrm{W}$ in Algeria. Another small cloud can be found in Niger at $14.5^{\circ} \mathrm{N}, 4^{\circ} \mathrm{E}$. All these features are very well visible in Fig. 5b. However, the MERIS cloud screening algorithm detects also a bright cloud over Mali (lower left corner; $16-20^{\circ} \mathrm{N}, 2-4^{\circ} \mathrm{W}$ ), which seems not to occur in the MERIS satellite image. Most probably, this misclassification is related to a desert dust storm and is interpreted as a cloud by the brightness-test (dust storms are usually as bright as clouds). Therefore, we included the SCIAMACHY dust index (see Sect. 3.3) which is able to distinguish between a cloud and a dust storm. Unfortunately, the performance of the dust index cannot be demonstrated for this case in Fig. 5c showing the SCIAMACHY cloud fraction, because the instrument operated in limb mode at this time. But there is another similar situation at the Prime Meridian and $28^{\circ} \mathrm{N}$, where the MERIS cloud screening results in more clouds than actually appear in the MERIS RGB image. By comparing Figure 5a and Figure 5c, one can see, that the cloud fraction values corresponds well to the MERIS RGB image since some of the ground pixels have been set to a value of 0.0 due to the dust index.

On the basis of the last two scenes, we will discuss the MICROS results concerning clouds over snow/ice covered regions. Since the MERIS instrument does not possess thermal infrared channels, which would provide valuable information for the cloud/snow/ice discrimination, topof-atmosphere (TOA) reflectance at $3.7 \mu$ derived from the AATSR instrument are also displayed for each example. Reflectances well below 0.1 correspond to clear land, water and snow/ice pixels, while values well above 0.1 indicate cloudy pixels.

First, we selected an orbit segment over Russia and the island Novaya Zemlya on the 3rd of May 2006 (orbit 21818) which is displayed in Fig. 6. The upper part of Fig. 6a includes cloud formations over the Barents Sea and most probably also over Novaya Zemlya (MERIS images looks blurry), whereas the Kara Sea is completely covered with sea ice (indicated by the cracks in the ice) with some very small clouds here and there. The upper right part of this orbit segment shows large snow fields on the mainland of Russia, which are most likely free of any clouds, at least it is true for that part where we can make a reference to the thermal infrared measurements of AATSR (Fig. 6d). Moreover, the RGB image 
(a)

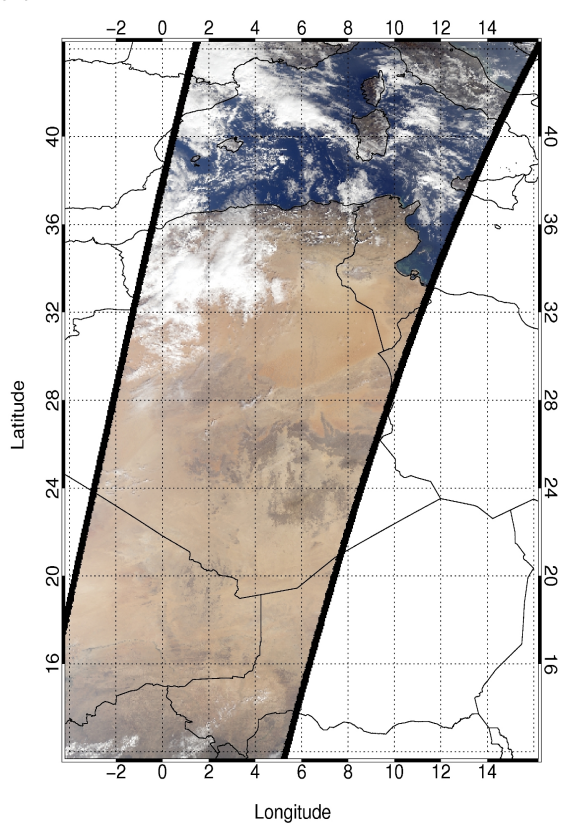

(b)

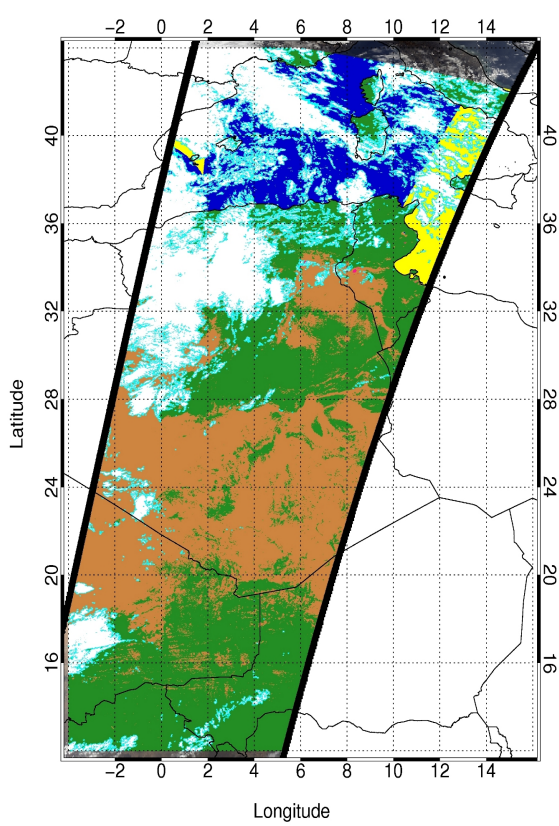

Longitude

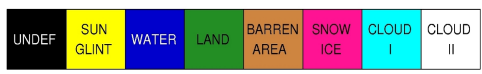

(c)
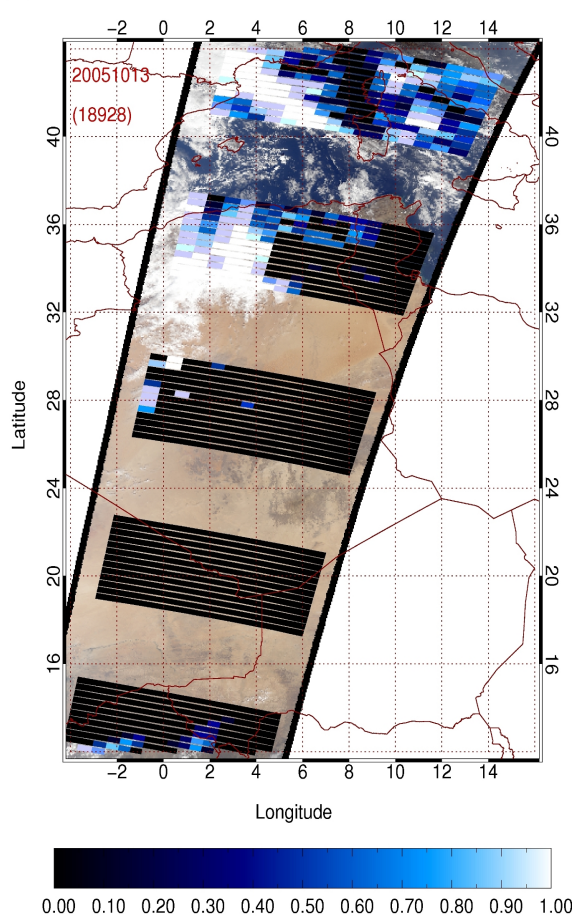

Fig. 5. Maps illustrating a section of orbit 18928 on the 13th of October 2005 covering North Africa and some part of the Mediterranean Sea: (a) MERIS RGB image, (b) MICROS-MERIS cloud screening and (c) MICROS-SCIAMACHY cloud fraction (at nadir).

contains clear land (lower left scene) as well as a large cloud field extending towards the Barents Sea (middle part of the scene). On the whole, the MICROS algorithm provides results that are very similar to the MERIS satellite image and AATSR measurements, but reveals also some discrepancies regarding the cloud detection over snow and ice covered regions. For instance, the MERIS cloud screening (Fig. 6b) does not recognize some clouds over Novaya Zemlya and over the mainland close around $68^{\circ} \mathrm{N}, 60^{\circ} \mathrm{E}$, which could be related to optically thin clouds mixed with some portion of the underlying snow surface spectral properties. Obviously, MDSIX is not able to clearly distinguish between optically thin clouds and snow/ice in cases of mixed pixels.

The maps in Fig. 7 show the MERIS satellite image, MICROS results and AATSR observations for the Arctic Ocean on the 3rd of May 2006 (orbit 21820). On this day Svalbard, the archipelago in the Arctic Ocean ranging from $76^{\circ}$ to $81^{\circ}$ north latitude and $10^{\circ}$ to $35^{\circ}$ east longitude, is almost cloud free beside some clouds in the north at around $79^{\circ} \mathrm{N}, 15^{\circ} \mathrm{E}$ (Fig. 7a). The MERIS cloud screening (Fig. 7b) results in clear snow and ice for Svalbard surrounded by clear water and sea ice (covered with snow), and thus, agrees very well with the study of Kokhanovsky and Schreier (2008) who investigated the snow albedo for the same day using combined AATSR and MERIS observations.
The Franz Josef Land is another archipelago situated in the Arctic Ocean, (north of Novaya Zemlya and east of Svalbard) that is occurring in the scene. Taking a closer look at the AATSR swath in the range from $45^{\circ}$ to $90^{\circ}$ east longitude (Fig. 7d), one can see clearly, that this part is extremely cloudy. The MERIS cloud screening gives almost the same result but misses a few thinner clouds over the western region of the archipelago.

Continuing the AATSR swath to the east, one encounters another archipelago, called Severnaya Zemlya. It is located off mainland Siberia's Taymyr Peninsula across the Vilkitsky Strait. According to the TOA reflectance at $3.7 \mu$, the archipelago and its closest surroundings seem to be free of bright, thick clouds which agrees well with the MERIS cloud screening. However, the cloud screening algorithm identifies a mixture of thin and thick clouds north of Severnaya Zemlya which are not visible in the AATSR map by such an extent. Possibly there are some optically thin clouds, but generally, the MERIS cloud screening seems to overestimate clouds in that area.

Further east between $110^{\circ}-125^{\circ}$ east longitude and $80^{\circ}-$ $82^{\circ}$ north latitude, the cloud screening algorithm does not capture a bright cloud band that is occurring in the AATSR observations. In the very last part of the AATSR swath, beyond $125^{\circ}$ east longitude (Laptev Sea), the MERIS cloud 
(a)

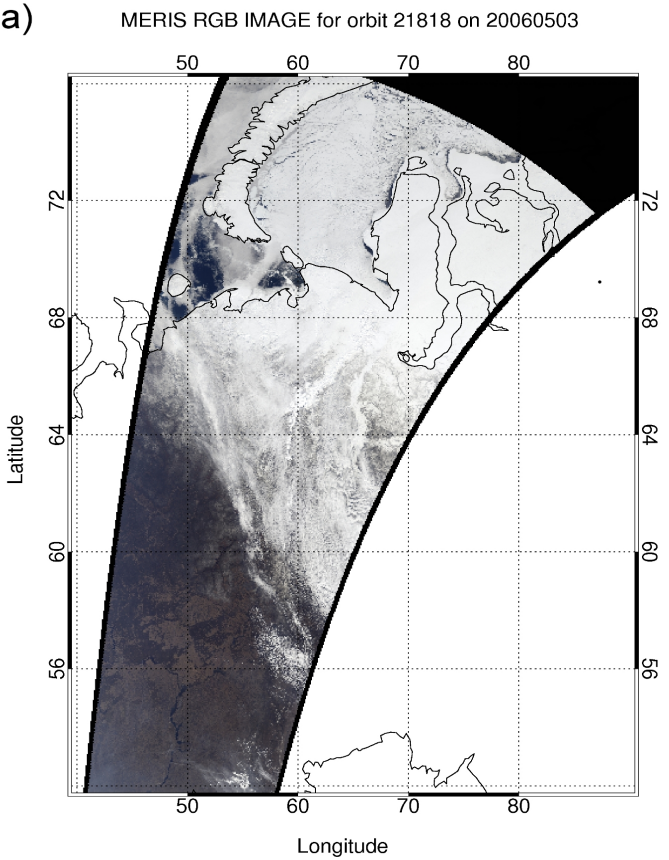

(c) MERIS RGB IMAGE and SCIAMACHY cloud fraction (total)

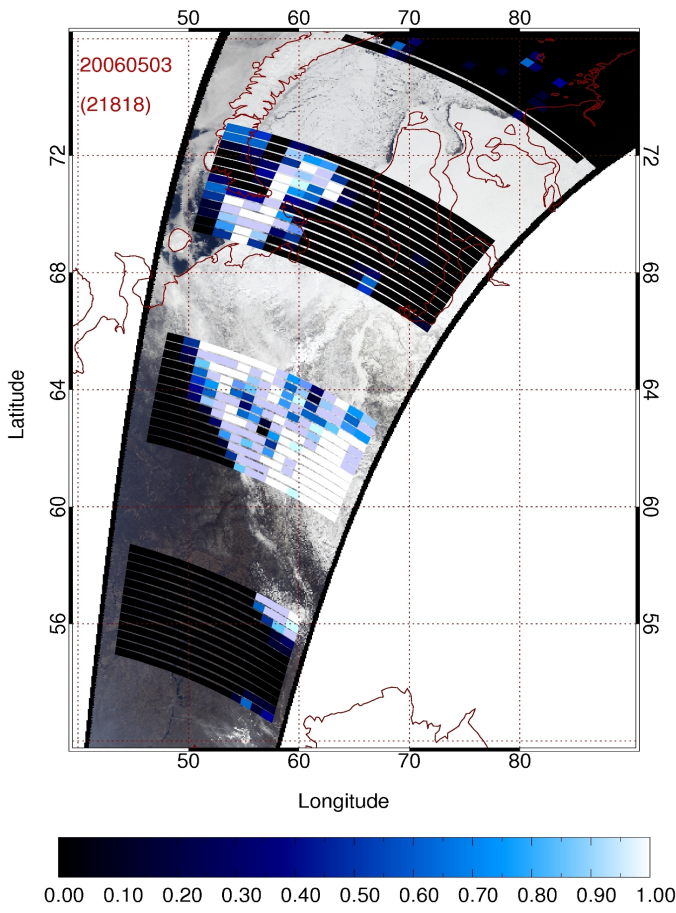

(b) MERIS Cloud Screening for orbit 21818 on 20060503
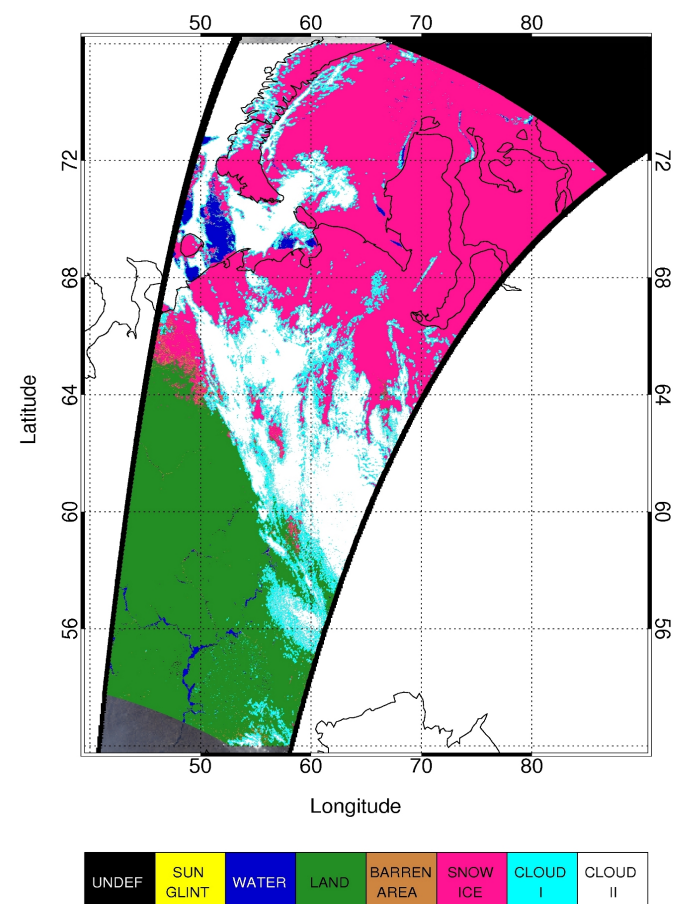

(d) MERIS RGB IMAGE and AATSR TOA Reflectance $3700 \mathrm{~nm}$

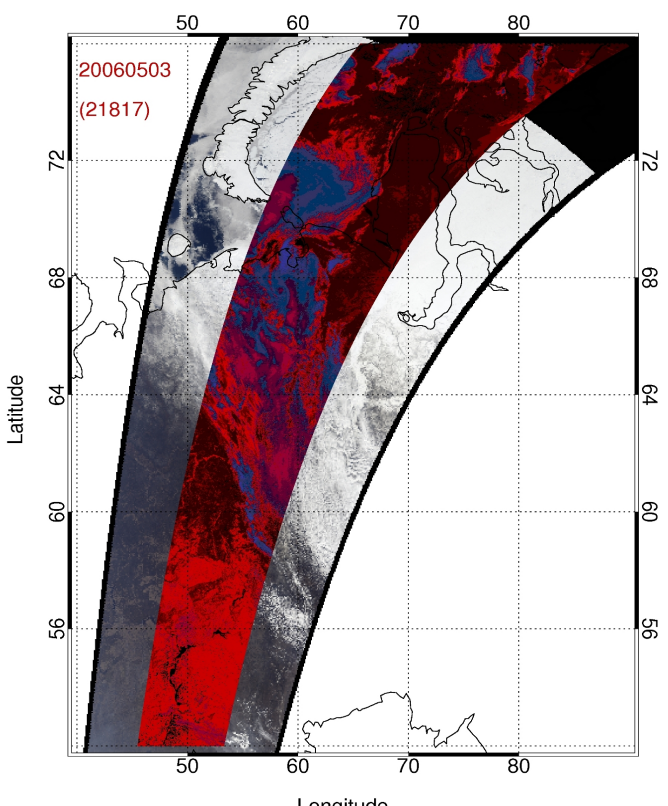

Longitude

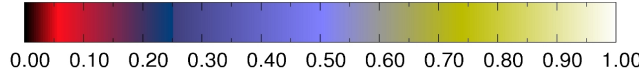

Fig. 6. Maps displaying some part of Russia and the island Novaya Zemlya on the 3rd of May 2006 (orbit 21818): (a) MERIS RGB image, (b) MICROS-MERIS cloud screening, (c) MICROS-SCIAMACHY cloud fraction (at nadir) and (d) top-of-atmosphere reflectance at 3.7 microns measured by AATSR/ENVISAT instrument. 
(a)

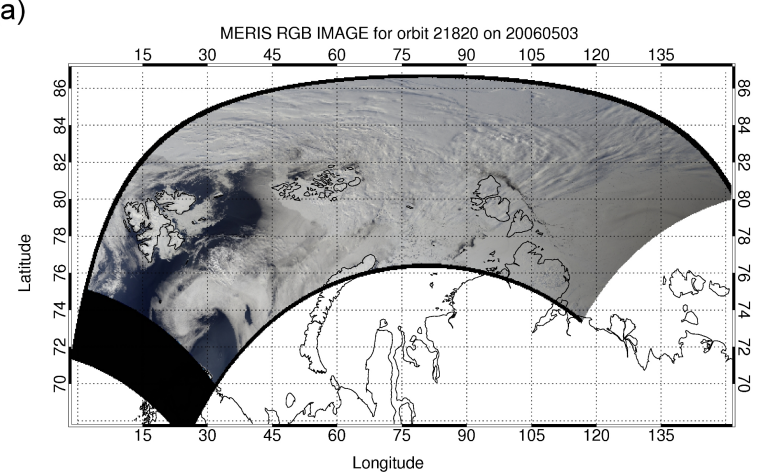

(c)

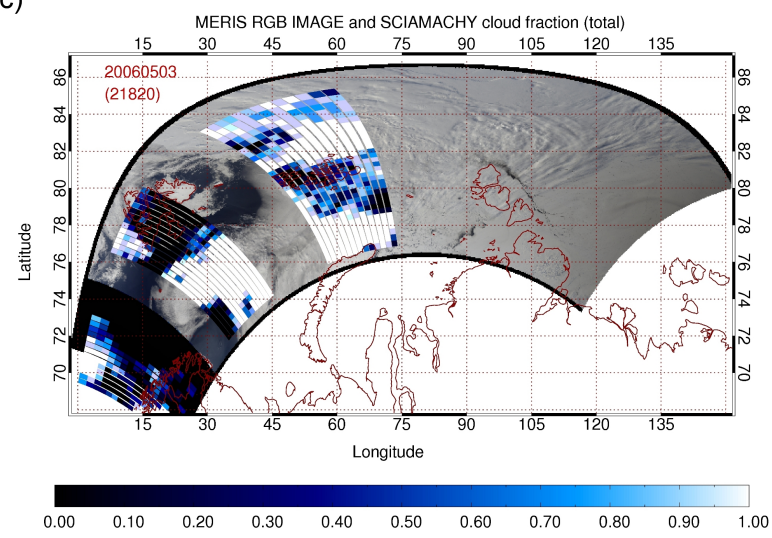

(b)

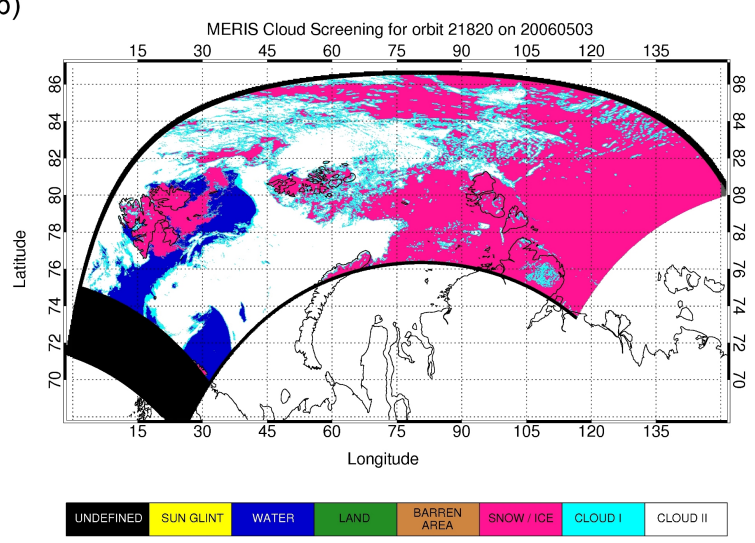

(d)

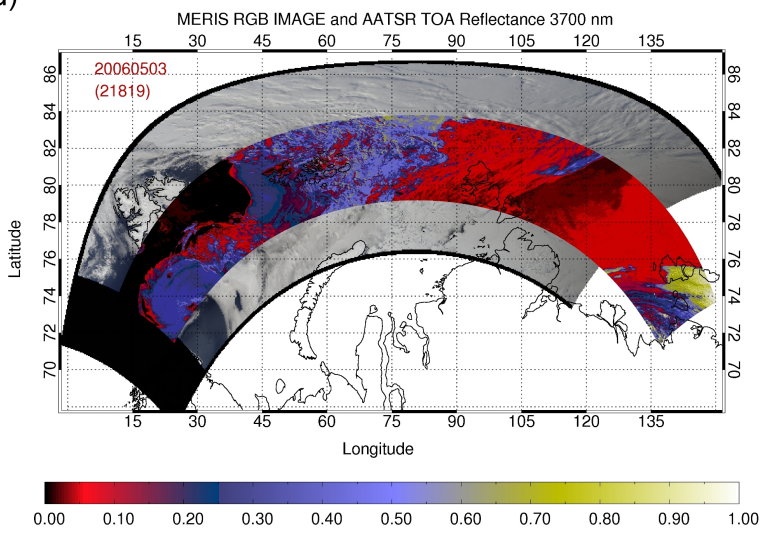

Fig. 7. Maps showing the Arctic Ocean on the 3rd of May 2006 (orbit 21820): (a) MERIS RGB image, (b) MICROS-MERIS cloud screening, (c) MICROS-SCIAMACHY cloud fraction (at nadir) and (d) top-of-atmosphere reflectance at 3.7 microns measured by AATSR/ENVISAT instrument.

screening coincides again with the thermal infrared measurements providing clear sea ice covered with snow.

In summary, these examples have demonstrated, that the MICROS algorithm leads to reasonable MERIS cloud screening and SCIAMACHY cloud fraction results in the whole. Nevertheless, some discrepancies occur in the course of the cloud/snow/ice discrimination which are related to the failure of MDSIX. As already discussed in Sect. 3.5, a clear snow/ice classification, that is simply based on spectral information obtained between $400 \mathrm{~nm}$ and $900 \mathrm{~nm}$, is almost impossible due to the different spectral behavior of snow and ice depending on its age, grain size, wetness and degree of pollution. Additional problems might be correlated with the different illumination and viewing geometries leading to wrong MDSIX values, and thus, to misclassifications regarding cloud detection over snow/ice in polar regions.

\subsection{Intercomparison with other algorithms}

The SCIAMACHY cloud fractions (with respect to optically thick clouds) derived from MICROS are intercompared with other current SCIAMACHY cloud fractions based on different approaches. For each of the following cross-validations we considered SCIAMACHY cloud fractions obtained from every 15th in 2007 (154 SCIAMACHY orbits).

First of all, we compared the SCIAMACHY cloud fractions obtained from MICROS and MCFA (Meris Cloud Fraction Algorithm) algorithms. MCFA is the previous version of MICROS and therefore, uses the same MERIS based technique to determine the SCIAMACHY cloud fractions. Figure 8a shows the intercomparison for 769891 SCIAMACHY ground scenes at nadir providing a correlation coefficient of 0.63 , which can be explained by Fig. 8b, illustrating the corresponding difference histogram of MICROS minus MCFA cloud fraction. In $10 \%$ of the cases, MCFA found fully cloudy pixels whereas MICROS identified noncloudy SCIAMACHY pixels, which for the most part are 
(a)

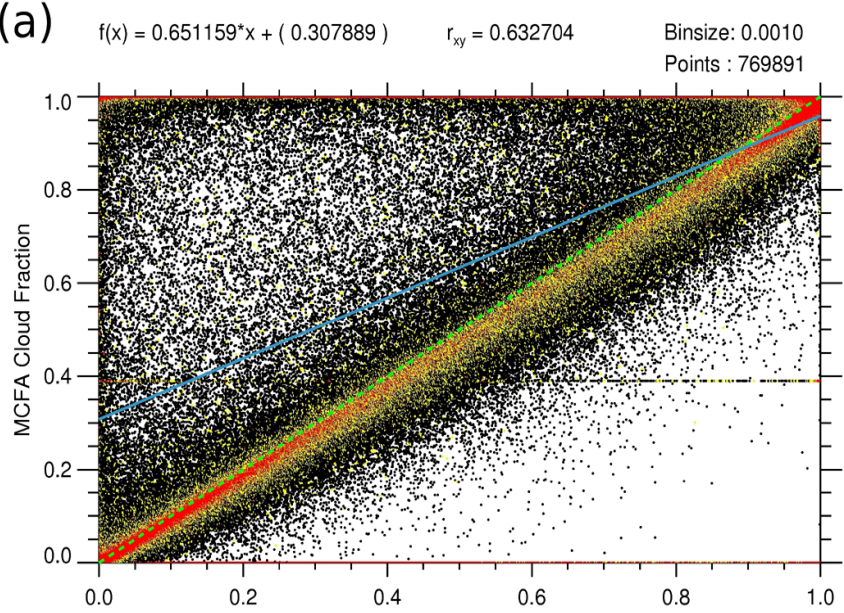

Date: $2007 \times \times 15$

(C)

0.2

MICROS Cloud Fraction

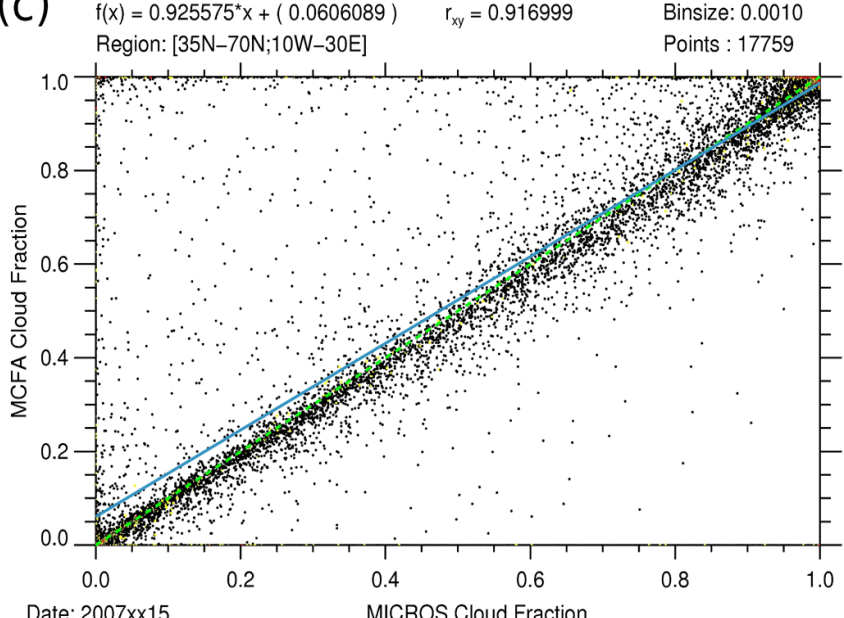

Date: $2007 \times x 15 \quad$ MICROS Cloud Fraction

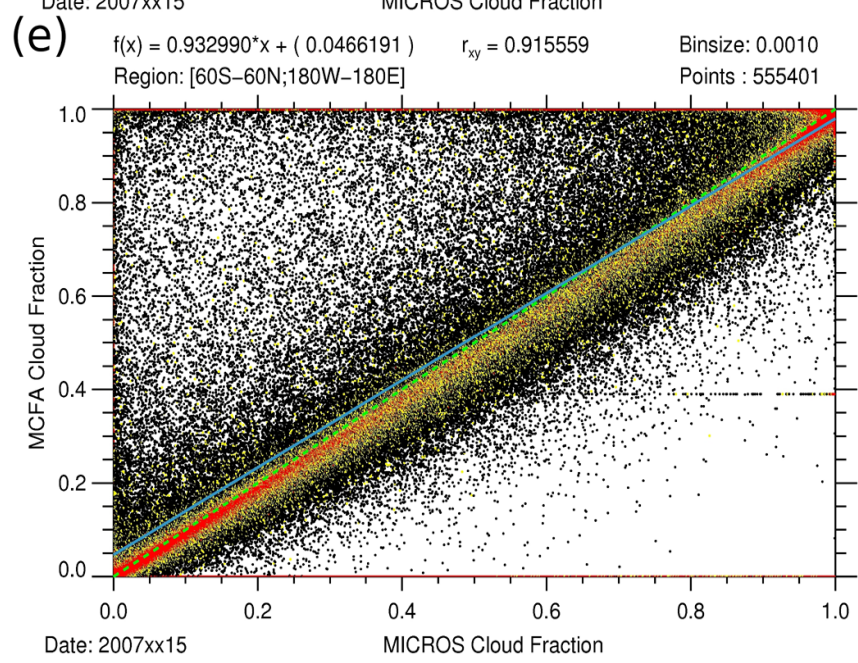

(b)

MICROS - MCFA

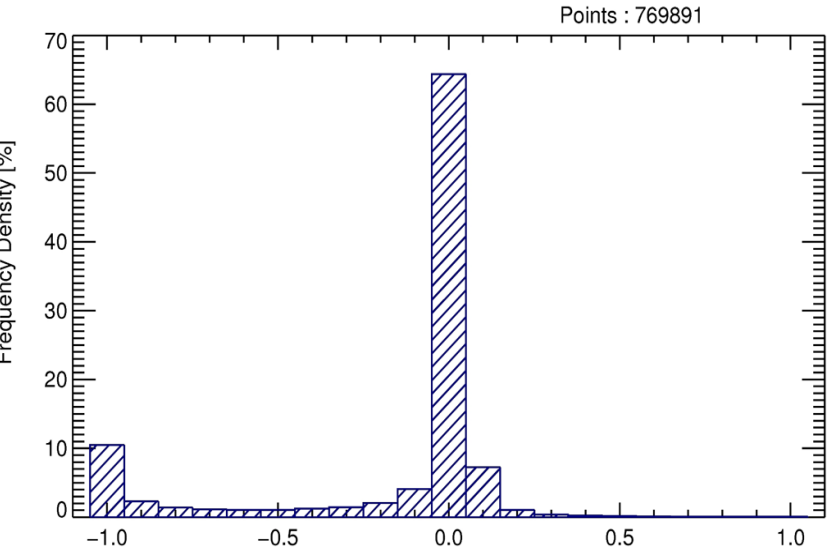

Date: $2007 \times \times 15$

SCIAMACHY cloud fraction (d)

d) $f(x)=0.975177^{\star} x+(-0.0157319) \quad r_{x y}=0.966634 \quad$ Binsize: 0.0010

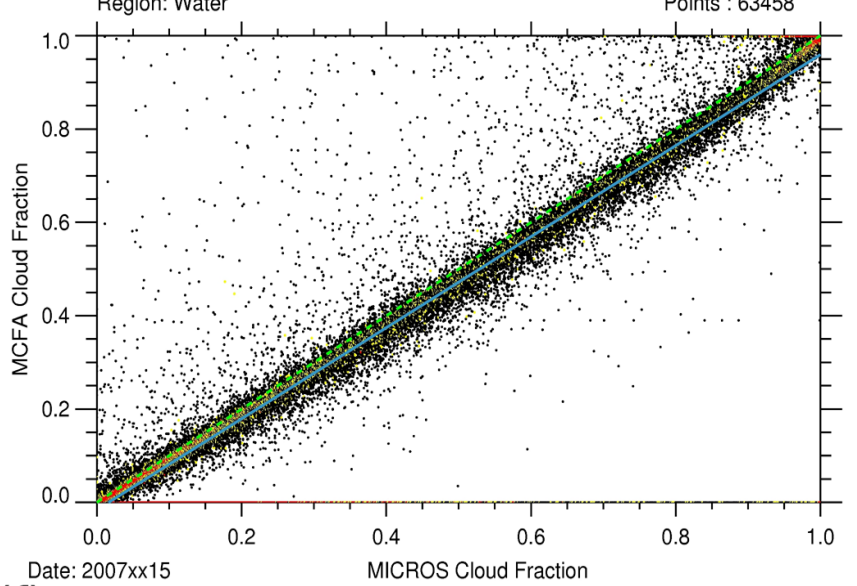

(f)

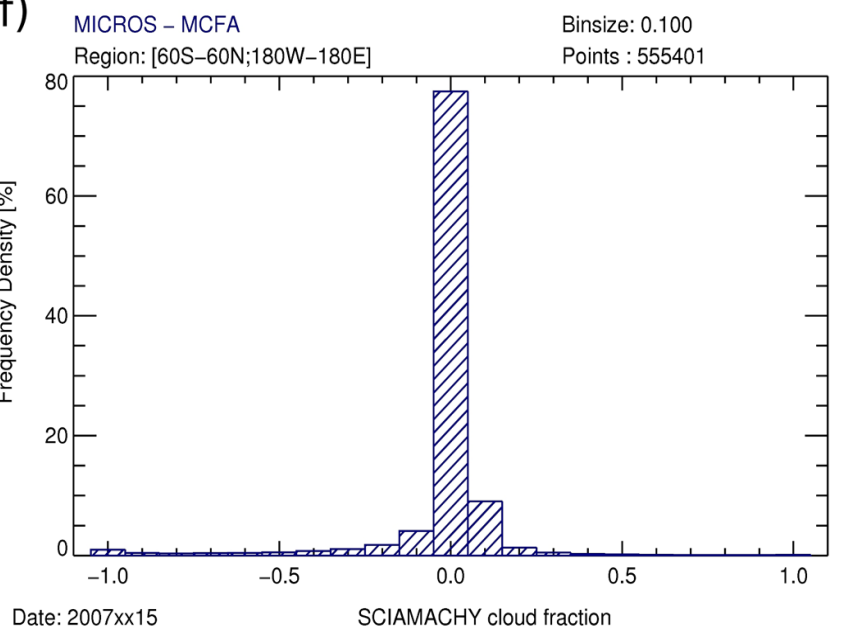

Fig. 8. Intercomparison of SCIAMACHY cloud fractions (optically thick clouds) derived from the MICROS and MCFA algorithms considering each 15th in 2007: (a) Cross-validation for all cloud fractions, (b) difference histogram with respect to (a), (c) cloud fractions over Europe $\left[35^{\circ} \mathrm{N}-70^{\circ} \mathrm{N} ; 10^{\circ} \mathrm{W}-30^{\circ} \mathrm{E}\right]$, (d) cloud fractions over water, (e) cloud fractions at mid- and low-latitudes $\left[60^{\circ} \mathrm{S}-60^{\circ} \mathrm{N} ; 180^{\circ} \mathrm{W}-\right.$ $\left.180^{\circ} \mathrm{E}\right]$ and (f) difference histogram with respect to (e). The colour code of the two dimensional density function plots [(a), (c), (d), (e)] is the following: If only one measurement is located inside of a bin, the result is coloured in black. If more than 1 but less than 4 measurements are located inside of a bin, the result is coloured in yellow. If more than 4 measurements are located inside of a bin, the results is coloured in red. 
(a) $f(x)=0.451393^{*} x+(0.186886) \quad r_{x y}=0.587891 \quad$ Binsize: 0.0010

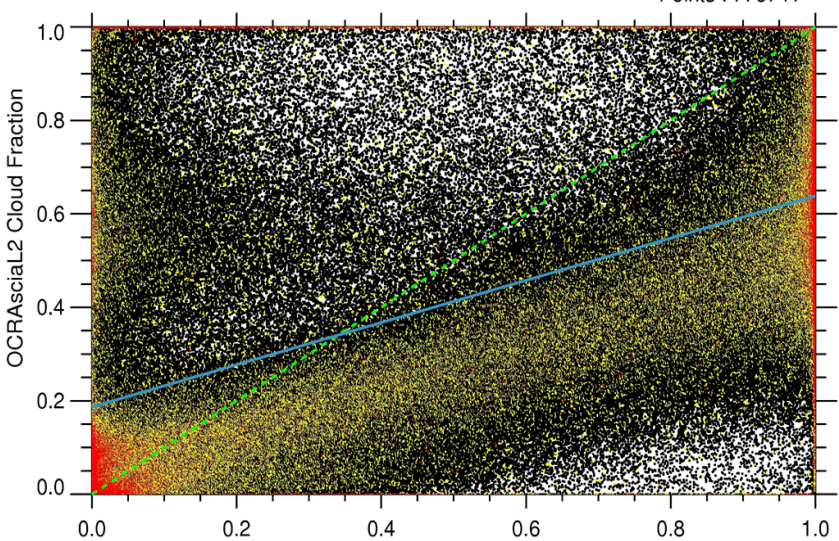
Date: $2007 \times x 15$ (c)
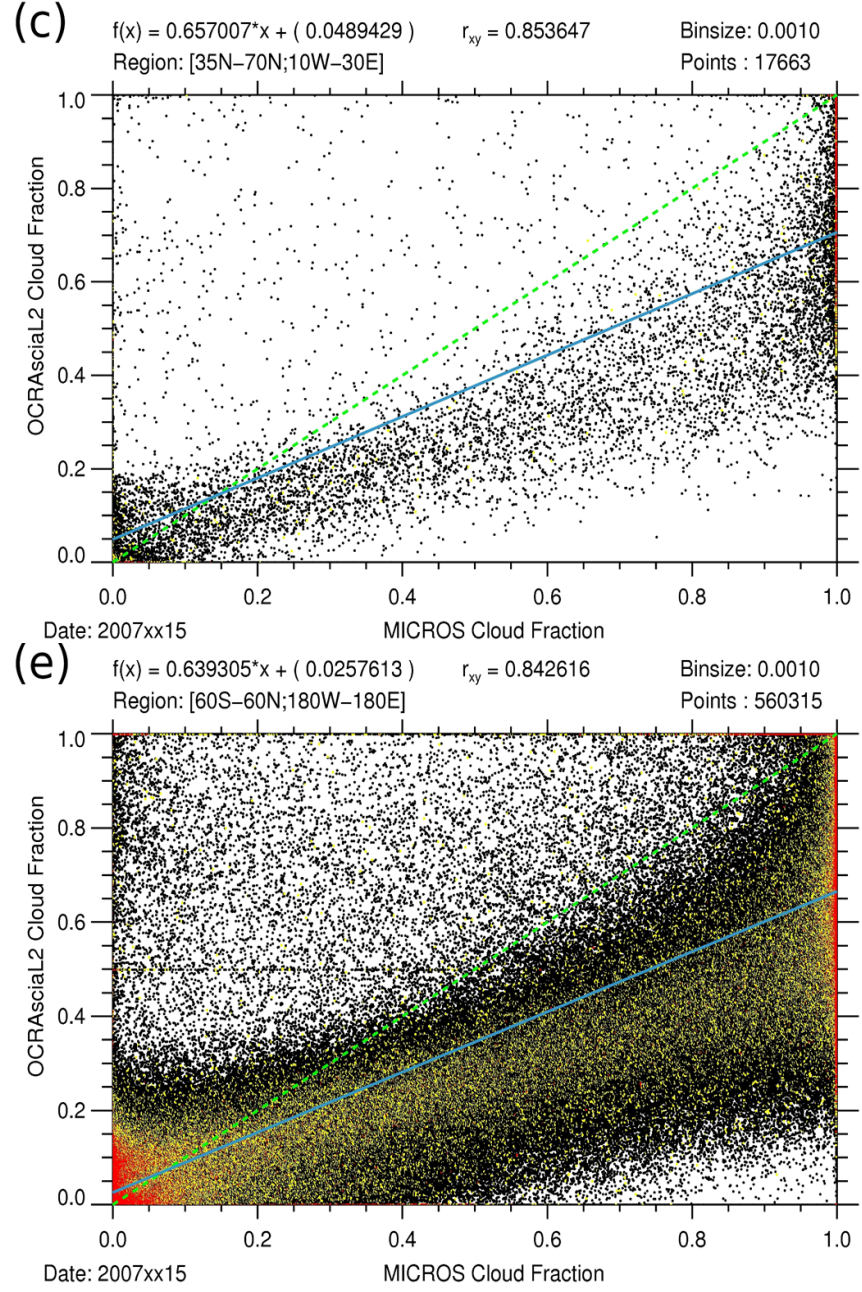

(b)

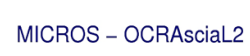

Binsize: 0.100

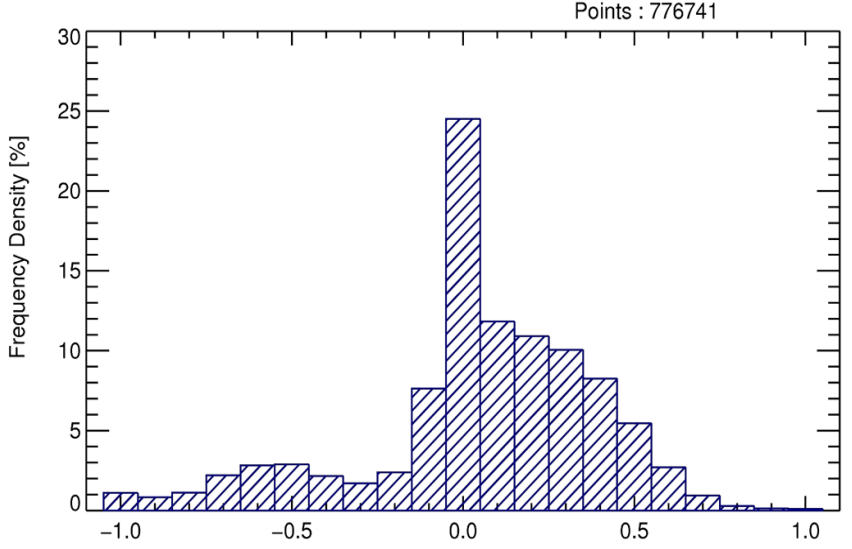

Date: $2007 \times \times 15$

SCIAMACHY cloud fraction

(d)

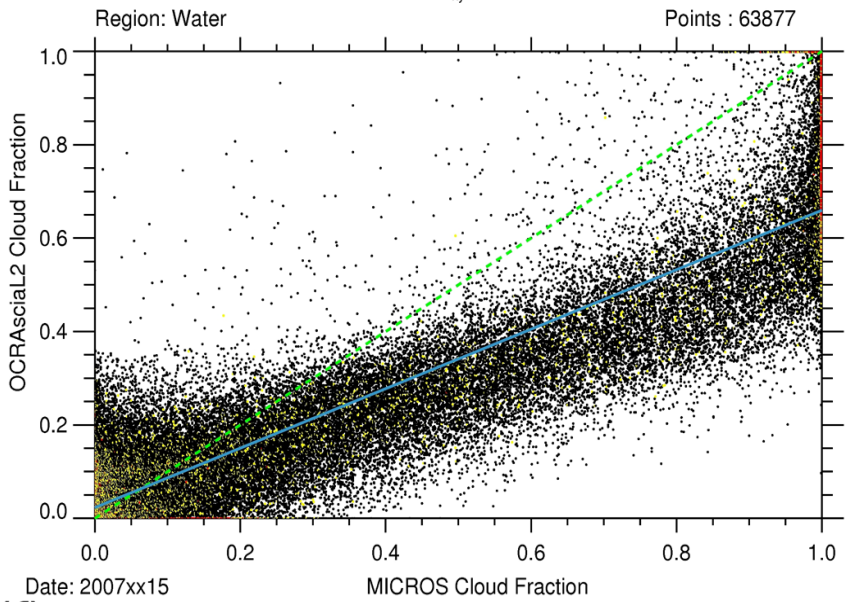

(f)

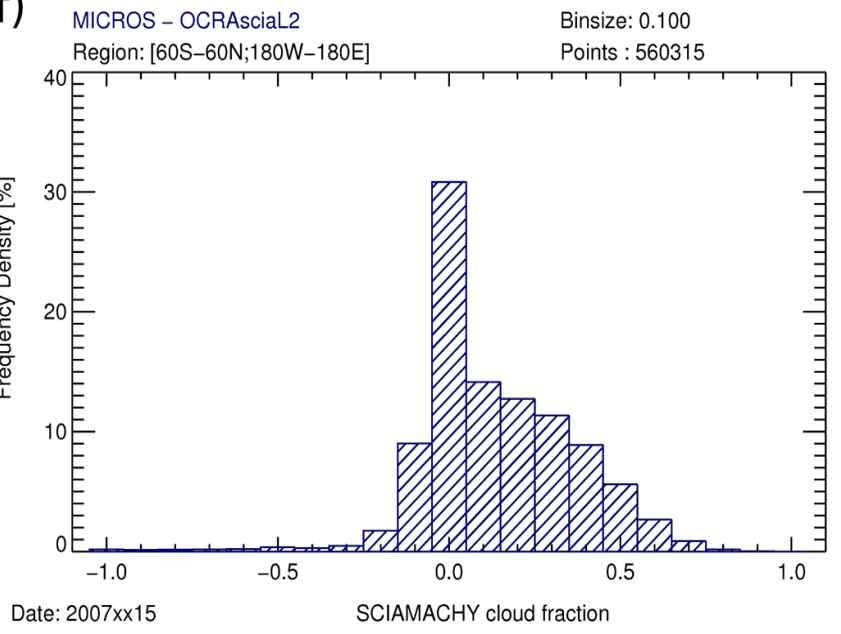

Fig. 9. Intercomparison of SCIAMACHY cloud fractions derived from the MICROS (optically thick clouds) and OCRA algorithms considering each 15th in 2007: (a) Cross-validation for all cloud fractions, (b) difference histogram with respect to (a), (c) cloud fractions over Europe $\left[35^{\circ} \mathrm{N}-70^{\circ} \mathrm{N} ; 10^{\circ} \mathrm{W}-30^{\circ} \mathrm{E}\right]$, (d) cloud fractions over water, (e) cloud fractions at mid- and low-latitudes $\left[60^{\circ} \mathrm{S}-60^{\circ} \mathrm{N}\right.$; $180^{\circ} \mathrm{W}-$ $\left.180^{\circ} \mathrm{E}\right]$ and (f) difference histogram with respect to (e). The colour code of the two dimensional density function plots $[(\mathbf{a}),(\mathbf{c}),(\mathbf{d}),(\mathbf{e})]$ is the following: If only one measurement is located inside of a bin, the result is coloured in black. If more than 1 but less than 4 measurements are located inside of a bin, the result is coloured in yellow. If more than 4 measurements are located inside of a bin, the results is coloured in red. 
related to ground scenes in polar regions. This is demonstrated by the cross-validation and difference histogram displayed in Fig. 8e and $\mathrm{f}$, where all cloud fractions at highlatitudes were excluded, leading to a considerably better correlation coefficient of 0.92 . Since MCFA was not designed to discriminate between clouds and very bright surface pixels, i.e., no MERIS Differential Snow Index (MDSIX) and Normalized Difference Vegetation Index (NDVI) are used, the algorithm overestimates clouds above bright surfaces. Moreover, we found that MICROS and MCFA cloud fractions are in very good agreement (above 90\%) over land and water, which is shown in Fig. 8c and d, respectively. In addition to MDSIX and NDVI, MICROS considers a land-water-mask, cloud borders and shadows, sun glint affected regions and the brightness of clouds (see Sect. 3), which are not taken into account in MCFA.

In summary, the shortcomings of MCFA are resolved in MICROS (in particular over snow) yielding a more accurate SCIAMACHY cloud fraction as demonstrated in Sect. 4.1 by comparing the MICROS results with MERIS satellite RGB images and thermal infrared measurements obtained from the AATSR instrument.

Figure 9 shows the intercomparison of SCIAMACHY cloud fractions based on MICROS and OCRA algorithms. The Optical Cloud Recognition Algorithm (OCRA) was developed by Loyola (1998) and is employed in the operational SCIAMACHY Level 2 processing. It is based on the Polarization Measurement Devices (PMDs) of SCIAMACHY which are 7 broadband detectors measuring the polarization of the incoming light (see Sect. 2). In this case, we found 776741 congruent SCIAMACHY ground scenes at nadir observation yielding a correlation coefficient of 0.59 , which is displayed in Fig. 9a. Figure 9b shows the corresponding difference histogram of MICROS minus OCRA cloud fraction. It is obvious that MICROS found more clear science pixel than OCRA, which might originate from the fact that in OCRA the cloud coverage is calculated by comparing the individual PMD sub-pixel to the previous stored cloud free composite reflectance database (Loyola, 1998). For the determination of the cloud-free composite reflectance database the so-called color space technique is used by defining "white" as an equal amount of radiation in three visible (red, green, blue) bands. Tuinder et al. (2004) found that due to this method an unnatural "patchy" behavior regarding the surface reflectances is produced in the course of the cloud-free database calculation, which means that the total amount of cloud coverage found in a science pixel might be caused from other features rather than real cloud features, especially when the retrieved cloud fraction is low. This might explain the low number of cloud free science pixels obtained by OCRA. If only cloud fractions at low- and midlatitudes are considered, as shown in Fig. 9e and f, the crossvalidation provides a significantly better correlation coefficient of about 0.84 . This implies that OCRA overestimates the cloud fraction over very bright surfaces due to the used method explained above. An intercomparison of cloud fractions located over Europe and water, displayed in Fig. 9c and $\mathrm{d}$, respectively, demonstrates that MICROS and OCRA are in good agreement $(\sim 85-90 \%)$ with respect of cloud detection of land and water. Note that in OCRA the PMDs (spatial resolution of about $30 \times 7 \mathrm{~km}^{2}$ ) are used as sub-pixel information leading to usually 8 PMD measurements in one $30 \times 60 \mathrm{~km}^{2}$ SCIAMACHY ground scene, while about 1800 spectral measurements obtained from MERIS reduced resolution data $\left(1.2 \times 1.2 \mathrm{~km}^{2}\right)$ are used for a nominal ground scene at nadir. The different spatial resolutions used in both algorithms will also cause disagreements in the intercomparison of SCIAMACHY cloud fractions.

It is important to note at this point, that we took OCRA cloud fractions derived from the SCIAMCHY Level 2 processing V3.01 where OCRA uses a GOME based minimum reflectivity database. The Global Ozone Monitoring Experiment (GOME) onboard the European Space Agency's European Remote Sensing 2 Satellite (ERS-2) has a ground pixel size of $320 \times 40 \mathrm{~km}$ and therefore, the GOME minimal reflectance database is not the best choice for a SCIAMACHY cloud fraction determination. It would be more fair to intercompare OCRA cloud fractions derived from the SCIAMACHY Level 2 processing V5.01 where the algorithm uses a SCIAMACHY based cloud-free composite reflectance database. However, at the time of writing SCIAMACHY Level 2 V5.01 data are only available for a low number of orbits. An intercomparison using a different data set (not shown here) of OCRA (V5.01) and MICROS cloud fractions showed that the cross-validation improves, especially in the case of satellite pixels having a low cloud fraction, which results from the fact that OCRA uses a more suitable minimal reflectance database.

Last but not least, an intercomparison for SCIAMACHY cloud fractions derived from MICROS and FRESCO algorithms was performed. It is important to note that FRESCO (Fast Retrieval Scheme for Clouds from the Oxygen A band) does not determine a geometric cloud fraction like MICROS or OCRA, but a so-called "effective" cloud fraction. The FRESCO algorithm makes use of reflectivities as measured by SCIAMACHY inside and outside the oxygen A band (758-778 nm), assuming an a priori chosen cloud optical thickness or cloud albedo (Koelemeijer et al., 2001; Wang et al., 2008). Despite the fact that, MICROS and FRESCO do not provide the same cloud fraction product and are using two very different approaches, the cross-validation yields a considerably high correlation coefficient of 0.85 for 631110 SCIAMACHY ground pixels at nadir, which is shown in Fig. 10a. Figure 10b displays the corresponding difference histogram of MICROS minus FRESCO+ cloud fraction demonstrating that the disagreement between both algorithms in cases of fully cloudy or non-cloudy pixels is less than $0.5 \%$. In general we found that, the FRESCO algorithm gives lower cloud fractions compared to those resulting from the MICROS approach. This is also shown by 
(a) $f(x)=0.635024^{*} x+(0.0448594) \quad r_{x y}=0.849918 \quad$ Binsize: 0.0010

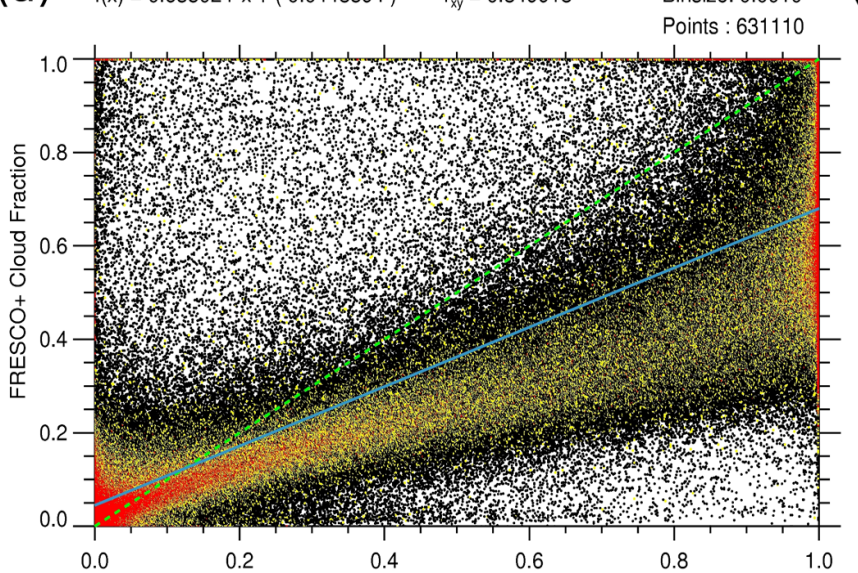

(b)

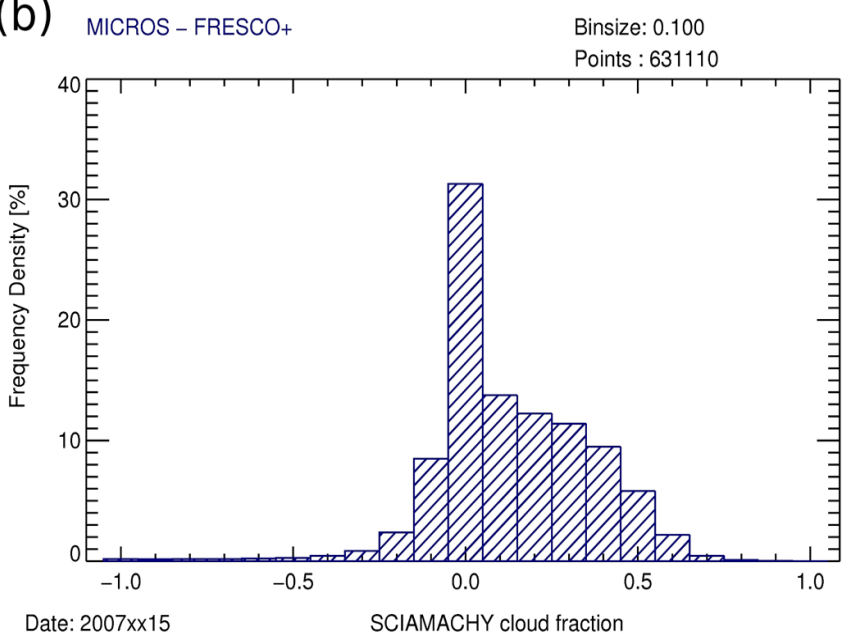

Date: $2007 \times x \times 15$

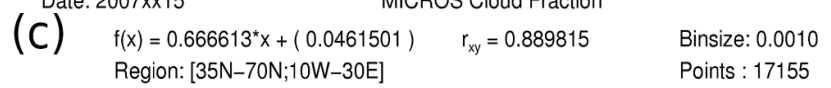

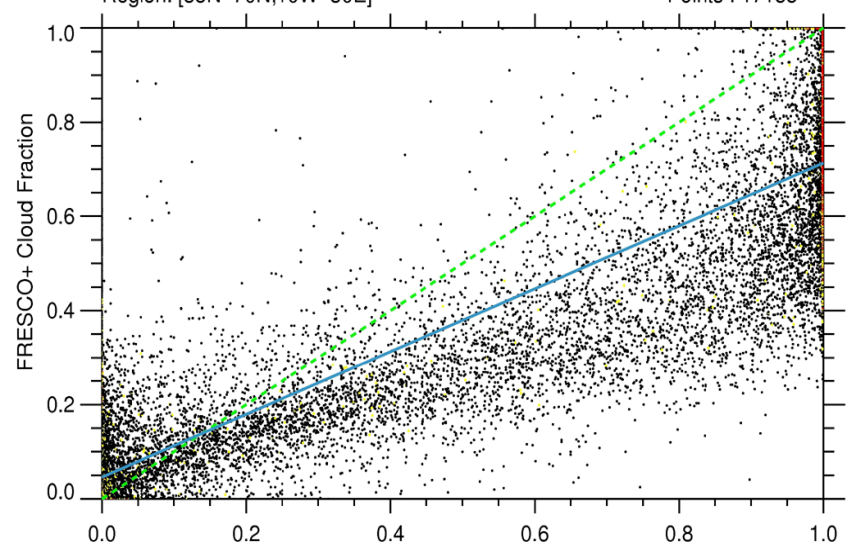

Date: $2007 \times 15$

(e) (d)

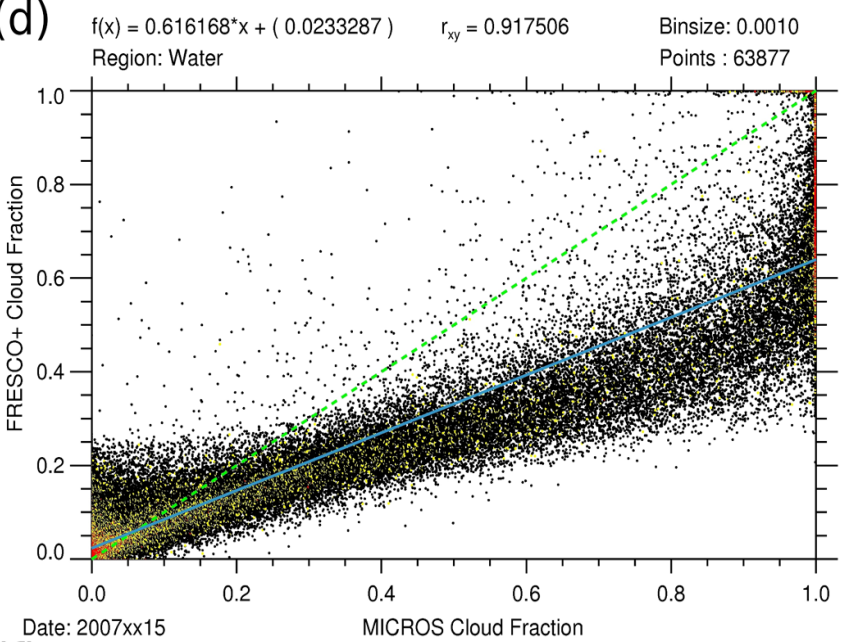

(f)

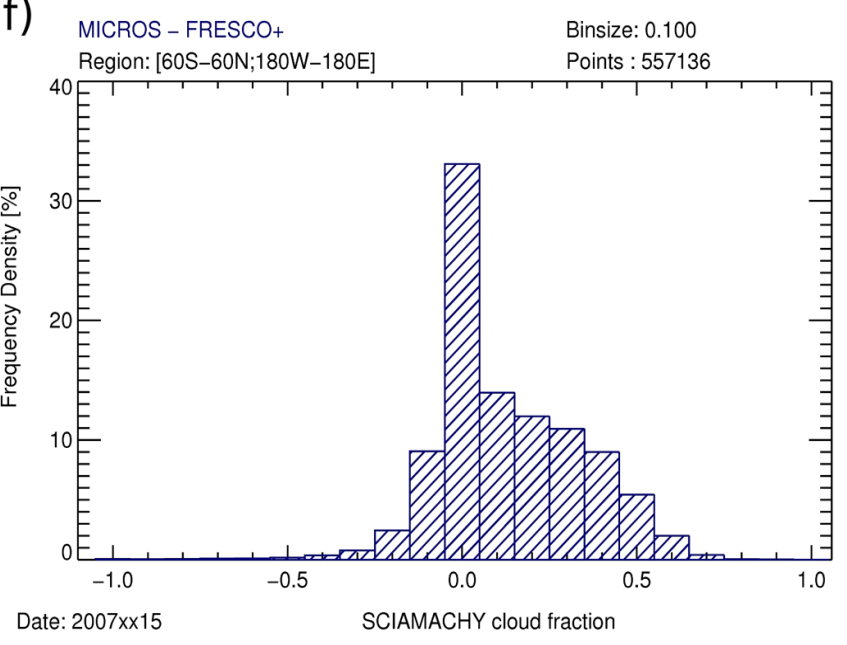

Fig. 10. Intercomparison of SCIAMACHY cloud fractions derived from the MICROS (optically thick clouds) and FRESCO+ algorithms considering each 15th in 2007: (a) Cross-validation for all cloud fractions, (b) difference histogram with respect to (a), (c) cloud fractions over Europe $\left[35^{\circ} \mathrm{N}-70^{\circ} \mathrm{N} ; 10^{\circ} \mathrm{W}-30^{\circ} \mathrm{E}\right]$, (d) cloud fractions over water, (e) cloud fractions at mid- and low-latitudes $\left[60^{\circ} \mathrm{S}-60^{\circ} \mathrm{N} ; 180^{\circ} \mathrm{W}-\right.$ $180^{\circ} \mathrm{E}$ ] and (f) difference histogram with respect to (e). The colour code of the two dimensional density function plots [(a), (c), (d), (e)] is the following: If only one measurement is located inside of a bin, the result is coloured in black. If more than 1 but less than 4 measurements are located inside of a bin, the result is coloured in yellow. If more than 4 measurements are located inside of a bin, the results is coloured in red. 
the other cross-validations where cloud fractions above Europe (Fig. 10c), above water (Fig. 10d) or at mid- and lowlatitudes (Fig. 10e) were selected. The difference histogram for the cloud fractions between $60^{\circ}$ south and $60^{\circ}$ north in Fig. 10f looks very similar to that in Fig. 10b. The lower number of ground pixels used in this intercomparison is associated with the incapability of FRESCO to derive an "effective" cloud fraction over snow/ice covered regions, which is indicated by an error flagging in the FRESCO+ product. Therefore, we excluded these science pixels in order to provide a fair comparison.

\section{Conclusions}

A new algorithm has been developed to determine an accurate geometric cloud fraction for a SCIAMACHY ground scene at nadir using MERIS spectral measurements. For the classification of the MERIS pixels, in either clear or cloudy, a set of thresholds and constraints are utilized. The SCIAMACHY cloud fraction is then defined as the ratio of the number of cloudy MERIS pixels to the total number of MERIS pixels that are located inside of the corresponding SCIAMACHY pixel.

The MICROS algorithm is the improved version of MCFA (MERIS cloud fraction Algorithm) (Kokhanovsky et al., 2009), which is the previous algorithm based on the same approach with several shortcomings, especially regarding the cloud detection over bright surfaces as discussed in Sect. 4.2. More precisely, the newly developed algorithm incorporates a digital elevation model and considers sun glint affected regions via geometrical considerations. Furthermore, MICROS is able to identify bright surfaces, such as barren areas of rock, sand, snow or ice, by means of the Normalized Difference Vegetation Index (NDVI) and the MERIS Differential Snow Index (MDSIX). Additionally, the brightness of clouds as well as cloud borders and shadows are taken into account in the new algorithm.

However, one weak point of MICROS (and also of MCFA) is the definition of optically thin and thick clouds. Generally, an optically thin cloud is considered as a thin cloud when the underlying surface is still visible. In the course of a cloud screening approach we do not have this information and therefore, we use the minimal reflectance value (RMIN) between $412 \mathrm{~nm}$ and $753 \mathrm{~nm}$ in conjunction with the spectral contrast in the blue (whiteness-test) in order to distinguish between optically thin $(\mathrm{RMIN}<0.2)$ and thick $(\mathrm{RMIN} \geq 0.2)$ clouds. Hence, one should keep in mind, that thin clouds detected by the MICROS algorithm should be regarded rather as sub-pixel or fractional clouds than as optically thin clouds.

Moreover, we found in MICROS a systematical overestimation of clouds with respect to sub-pixel clouds. This sideeffect does not play an important role for aerosol retrievals using the MICROS cloud fraction since $100 \%$ cloud free pix- els are needed in this case, but it must be taken into account for cloud optical property retrievals.

The MICROS algorithm provides three different SCIAMACHY cloud fractions, namely a thin cloud fraction, a thick cloud fraction and a total (thin and thick) cloud fraction. In addition to the SCIAMACHY cloud fraction data file, MICROS delivers two more data files, containing the averaged MERIS reflectances (with respect to clear pixels) and MERIS pixel classification, respectively. The MERIS reflectances for the SCIAMACHY ground scene at nadir are produced in a similar way as the cloud fraction, i.e. by averaging over all clear MERIS pixels inside of the corresponding SCIAMACHY ground pixel.

A qualitative validation of the MICROS results was presented in Sect. 4.1. The comparison between our new developed MERIS cloud screening and MERIS satellite images as well as AATSR spectral measurements indicates that MICROS is capable of providing a reliable MERIS pixel classification (sun glint, water, land, barren area, snow/ice and cloudy pixels). Consequently, MICROS determines accurate SCIAMACHY cloud fractions for nadir observations that can be used as input parameter for aerosol, trace gas and cloud optical property retrievals.

\section{Outlook}

So far, only a qualitative validation of the MICROS algorithm was carried out by comparing the results with MERIS satellite images and thermal infrared observations derived from the AATSR instrument. However, a quantitative validation using meteorological datasets, for instance METAR (MÉTéorologique Aviation Réguliére - a network for the provision of meteorological data for aviation), is also very crucial and will be accomplished next.

In the MICROS algorithm clouds are considered as bright and white objects by means of a brightness and whiteness test, respectively. The two other remaining characteristica which are related to the temperature and height of clouds are not incorporated up to now. Thus, further improvements of the MERIS cloud screening, especially with respect to the cloud detection over snow and ice covered regions, can be achieved using the two residual criteria as additional information.

In Sect. 3.5 we have discussed the complexity to distinguish between clouds and snow/ice using only spectral measurements in the visible and near infrared wavelength regions, since both offer spectral behaviors that are similar in shape and magnitude. The AATSR instrument, which is another instrument on board ENVISAT, provides the opportunity to utilize spectral information in the thermal infrared wavelength region. Hence, one could exploit the fact that clouds are usually cold by carrying out a brightness temperature test $\left[\mathrm{B}_{T}(3.7 \mu), \mathrm{B}_{T}(11 \mu)\right.$ or $\left.\mathrm{B}_{T}(12 \mu)\right]$, and/or using channel $10.8 \mu$ to calculate the reflectance at $3.7 \mu$ out 
of $\mathrm{B}_{T}(3.7 \mu)$ (Istomina et al., 2010). However, the synergy with AATSR entails one disadvantage, namely that the swath width of AATSR amounts to $500 \mathrm{~km}$ only, lying in the middle of the MERIS swath width which is around $1150 \mathrm{~km}$. Thus, it is not possible to cover the full SCIAMACHY state and consequently, some of the ground pixels on both sides of the state will not be considered in the course of the SCIAMACHY cloud fraction determination.

The other possibility to further advance the MERIS cloud detection is associated with the oxygen absorption band of the MERIS instrument in order to take advantage of the feature, that clouds are usually well above the surface. The cloud height information can be used then as an additional test, which would be particularly useful for the distinction between clouds and very bright surfaces.

We would like to stress that the cloud screening part of the MICROS algorithm could be important for the upcoming ESA's SENTINEL-3 mission (GMES MEDIUM RESOLUTION LAND AND OCEAN MISSION) which is planned for launch in the last quarter of 2012. On board the SENTINEL3 satellite there will be instruments in continuation of MERIS and AATSR, namely the OLCI (Ocean and Land Colour Instrument) and SLST (Sea and Land Surface Temperature) instruments, respectively. Both instruments offer much broader swath widths (1270 km and $1675 \mathrm{~km}$ ), compared to MERIS and AATSR instruments $(1150 \mathrm{~km}$ and $500 \mathrm{~km})$ on board the ENVISAT satellite, which leads to a very good synergy result between OLCI and SLST.

Acknowledgements. This work has been performed in the framework of the DFG RESINC-2 project. The authors are grateful to ESA for the possibility to use MERIS and SCIAMACHY data. We would also like to thank M. Vountas and H. Bovensmann for their help and assistance. Discussions with B. Mayer are much appreciated.

Edited by: C. von Savigny

\section{References}

Ackerman, S., Strabala, K., Menzel, P., Frey, R., Moeller, C., Gumley, L., Baum, B., Wetzel Seemann, S., and Zhang, H.: Discriminating clear-sky from cloud with MODIS, Algorithm Theoretical Basis Document, http://modis-atmos.gsfc.nasa.gov/ reference_atbd.php, 2006.

Bezy, J. L. and Rast, M.: The ESA Medium Resolution Imaging Spectrometer MERIS a review of the instrument and its mission, Int. J. Remote Sens., 20, 1681-1702, doi:10.1080/014311699212416, 1999.

Bourg, L., D'Alba, L., and Colagrande, P.: MERIS Smile Effect Characterisation and Correction, Technical Note, Issue 2 (http://earth.esa.int/pcs/envisat/meris/documentation/MERIS_ Smile_Effect.pdf), European Space Agency (ESA), 2008.

Bovensmann, H., Burrows, J. P., Buchwitz, M., Frerick, J., Noël, S., Rozanov, V. V., Chance, K. V., and Goede, A. P. H.: SCIAMACHY: Mission Objectives and Measurement Modes,
J. Atmos. Sci., 56, 127-150, doi:10.1175/1520-0469(1999)056, 1999.

Grzegorski, M., Wenig, M., Platt, U., Stammes, P., Fournier, N., and Wagner, T.: The Heidelberg iterative cloud retrieval utilities (HICRU) and its application to GOME data, Atmos. Chem. Phys., 6, 4461-4476, doi:10.5194/acp-6-4461-2006, 2006.

Istomina, L. G., von Hoyningen-Huene, W., Kokhanovsky, A. A., and Burrows, J. P.: The detection of cloud-free snow-covered areas using AATSR measurements, Atmos. Meas. Tech., 3, 10051017, doi:10.5194/amt-3-1005-2010, 2010.

Koelemeijer, R. B. A., Stammes, P., Hovenier, J. W., and de Haan, J. F.: A fast method for retrieval of cloud parameters using oxygen a band measurements from the Global Ozone Monitoring Experiment, J. Geophys. Res., 106, 3475-3490, doi:10.1029/2000JD900657, 2001.

Koelemeijer, R. B. A., Stammes, P., Hovenier, J. W., and de Haan, J. F.: Global distributions of effective cloud fraction and cloud top pressure derived from oxygen A band spectra measured by the Global Ozone Monitoring Experiment: Comparison to ISCCP data, J. Geophys. Res., 107(D12), 4151, doi:10.1029/2001JD000840, 2002.

Kokhanovsky, A. A. and Schreier, M. (Eds.): The determination of snow albedo using combined AATSR and MERIS observations, Proc. of the 2nd MERIS/(A)ATSR User Workshop in Frascati, Italy, 2008.

Kokhanovsky, A. A., Rozanov, V. V., Zege, E. P., Bovensmann, H., and Burrows, J. P.: A semianalytical cloud retrieval algorithm using backscattered radiation in $0.4-2.4 \mu \mathrm{m}$ spectral region, J. Geophys. Res., 108(D1), 4008, doi:10.1029/2001JD001543, 2003.

Kokhanovsky, A. A., von Hoyningen-Huene, W., and Burrows, J. P.: The determination of the cloud fraction in the SCIAMACHY ground scene using MERIS spectral measurements, ATBD (www.iup.uni-bremen.de/ $\sim$ sciaproc/MCF/DOCU/ GPOD_ATBD_Feb_2007_draft_8.pdf), University of Bremen, Institute of Environmental Physics, 2007.

Kokhanovsky, A. A., von Hoyningen-Huene, W., and Burrows, J. P.: Determination of the cloud fraction in the SCIAMACHY ground scene using MERIS spectral measurements, Int. J. Remote Sens., 30, 6151-6167, doi:10.1080/01431160902842326, 2009.

Krijger, J. M., Aben, I., and Schrijver, H.: Distinction between clouds and ice/snow covered surfaces in the identification of cloud-free observations using SCIAMACHY PMDs, Atmos. Chem. Phys., 5, 2729-2738, doi:10.5194/acp-5-2729-2005, 2005.

Lotz, W. A., Vountas, M., Dinter, T., and Burrows, J. P.: Cloud and surface classification using SCIAMACHY polarization measurement devices, Atmos. Chem. Phys., 9, 1279-1288, doi:10.5194/acp-9-1279-2009, 2009.

Loyola, D.: A new cloud recognition algorithm for optical sensors, IEEE International Geoscience and Remote Sensing Symposium, IGARSS, Seattle/WA, 6-10 July 1998, 572-574, 1998.

Loyola, D.: Automatic cloud analysis from polar-orbiting satellites using neural network and data fusion techniques, IEEE International Geoscience and Remote Sensing Symposium, IGARSS, Anchorage/Alaska, 20-24 August 2004, 2530-2533, 2004.

Rozanov, V. V. and Kokhanovsky, A. A.: Semianalytical cloud retrieval algorithm as applied to the cloud top altitude and the cloud geometrical thickness determination from top-of-atmosphere re- 
flectance measurements in the oxygen A band, J. Geophys. Res., 109, D05202, doi:10.1029/2003JD004104, 2004.

Rozanov, V. V., Kokhanovsky, A. A., Loyola, D., Siddans, R., Latter, B., Stevens, A., and Burrows, J. P.: Intercomparison of cloud top altitudes as derived using GOME and ATSR-2 instruments onboard ERS-2, Remote Sens. Environ., 102, 186-193, doi:10.1016/j.rse.2006.02.009, 2006.

Tuinder, O. N. E., de Winter-Sorkina, R., and Builtjes, P. J. H.: Retrieval methods of effective cloud cover from the GOME instrument: an intercomparison, Atmos. Chem. Phys., 4, 255-273, doi:10.5194/acp-4-255-2004, 2004.

von Hoyningen-Huene, W., Freitag, M., and Burrows, J. P.: Retrieval of aerosol optical thickness over land surfaces from top-of-atmosphere radiance, J. Geophys. Res., 108(D9), 4260, doi:10.1029/2001JD002018, 2003.
Wang, P., Stammes, P., van der A, R., Pinardi, G., and van Roozendael, M.: FRESCO+: an improved $\mathrm{O}_{2}$ A-band cloud retrieval algorithm for tropospheric trace gas retrievals, Atmos. Chem. Phys., 8, 6565-6576, doi:10.5194/acp-8-6565-2008, 2008.

Zeng, Q., Cao, M., Feng, X., Liang, F., Chen, X., and Sheng, W. (Eds.): A study of spectral reflection characteristics for snow, ice and water in the north of China, no. 145 in Hydrological Applications of Remote Sensing and Remote Data Transmission, Proceedings of the Hamburg Symposium, 1983. 